\title{
Pressure and apparent voidage profiles for riser with an abrupt exit (T-shape) in a CFB riser operating above fast fluidization regimes
}

\author{
Esmail R. Monazam ${ }^{1}$, Ronald W. Breault ${ }^{2 *}$ and Lawrence J. Shadle ${ }^{2}$ \\ ${ }^{1}$ REM Engineering Services, PLLC \\ 3537 Collins Ferry Rd. \\ Morgantown, West Virginia 26505 \\ ${ }^{2}$ National Energy Technology Laboratory \\ U. S. Department of Energy \\ 3610 Collins Ferry Rd. \\ Morgantown, West Virginia 26507-0880
}

\begin{abstract}
The influence of abrupt exit (T-shaped) configurationon the riser axial pressure profile in a largescale circulating fluidized bed (CFB) are examined. A new analysis was developed to predict the axial voidage along the length of influence in the exit region with T-shape geometry. The exit region was characterized using non-dimensional analysis of the continuum equations (balances of masses and momenta) that described multiphase flows. In addition to deceleration length duo to abrupt exit, the boundary condition for the solids fraction at the top of the riser and the fully
\end{abstract}

*Corresponding Author, (304) 285-4486, ronald.breault@ netl.doe.gov 
developed regions, were measured using an industrial scale circulating fluidized bed (CFB) of 0.3

$\mathrm{m}$ diameter and $15 \mathrm{~m}$ tall. The operating factors affecting the flow development in the exit region were determined for three materials of various sizes and densitiesin core annular and dilute regimes of the riser. Performance data were taken from statistically designed experiments over a wide range of $\mathrm{Fr}$ (0.5-39), $\operatorname{Re}$ (8-600), Ar (29-3600), load ratio (0.2-28), riser to particle diameter ratio (375-5000), and gas to solids density ratio (138-1381). A series of correlations were developed to predict the voidage at the exit of the riser and length of influence due to the exit geometry. The correlations are based on gas and solid properties, operating conditions, and riser geometry.

\section{Introduction}

Circulating fluidized beds (CFBs) are utilized in many different applications, including combustion and gasification of coal, fluid catalytic cracking (FCC), fluid hydroforming, and the production of polyethylene[1]. The hydrodynamics of CFB risers is highly complex and there have been substantial efforts over the past two decades, with ultimate aim to improve the performance of the CFB. The flow behavior in CFB riser can be significantly affected with type and configuration of the exit used at the top of the riser. There are number of studies that examined the influence of exit geometry in circulating fluidized beds[2-6]. Grace [2] reviewed the effect of riser geometry on the axial and radial void fraction on the gas-solid flow. If the exit is at a sharp angle, the particles reflect off the top and recirculate internally down the wall of the riser. Senior [3] concluded that abrupt exits internally reflect a substantial portion of solids down the riser wall, while smooth exits allow the majority of upflowing solids to exit the riser. Senior used a reflection coefficient, $R_{\mathrm{f}}$ (ratio of downwards solids flow to upwards solid flow in the riser) to 
interpret his results. This coefficient is reported to be dependent on the geometry of the exit as well as the operating conditions for a given bed material. Brereton and Grace [4] reported that the exit geometry can influence pressure and voidage profiles along a considerable length of the riser and similarly used a reflection coefficient to explain the observed profiles. These studies provide a relative comparison of the solids holdup near the top of the riser between smooth flowing exit and an abrupt exit. However, this approach does not provide an estimate of the riser voidage profile, or the effect on solids holdup, without the baseline smooth flow geometry.

Lim et al. [5]noted that a strong exit restriction gives a C-shaped voidage profile, while a weak exit restriction does not. Zhang et al [6] reported that an abrupt exit can induce higher solids concentrations and heat transfer near the riser exit. Mabrouk et al. [7] investigated the exit region for an internally circulating riser system and found that axial solids hold-up proved to be a good indicator for the influences of various exits.

Harris et al. [8] developed a correlation to calculate the length of influence due to the exit. They concluded that the exit geometry in a CFB has a clear effect on the cross-sectional averaged solids concentration profile in a CFB riser. They applied the concept of reflection coefficient to estimate relative voidage profiles for various operating conditions and system exit configurations. Pugsley et al. [9] measured axial pressure profiles in risers of different diameter and heights using sand and FCC particles. They conclude that if the riser diameter and particle terminal velocity were large enough, the exit affect can extend all the way to the base of the riser. If the riser diameter was smaller, the refluxing particle layer could attain only a certain maximum thickness before the particles were re-entrained upward by the shearing action of the gas phase. Using the same 
concept, they report the gas solids slip factor relative to that determined using smooth-flow riser exit geometry. Unfortunately, it is difficult to readily change the exit geometry in a large scale riser. There is a need to estimate the effect of the exit geometry on the solids holdup and to determine the length of influence for the commonly used T-shaped exit.

T-shaped riser exit is employed in high temperature high velocity operations such as coal combustion with internal sulfur capture, coal gasification and hot gas cleanup with $\mathrm{ZnO}$ and supported sorbents. This configuration minimizes the effects of erosion and corrosion at the outlet. Several investigators report the effect of the T-shape exit geometry[4,10-13].Vanengelandt et al. [10] concluded that reducing the outlet surface area of a T-outlet resulted in higher axial and radial particle velocities in outlet region and in an increased solids hold-up in the dead zone above the exit. Kim et al. [11] applied chaos analysis to high speed pressure fluctuation data for three different exit geometries and found that the smooth bend exit was more stable than either an $\mathrm{L}$ or $\mathrm{T}$ type exit. Jinet al. [12] studied the effect of exit structure on the axial distribution of the solids concentration. When using ablind-T configuration, a significant increase of the solids concentration was observed at the top of the riser. Brereton and Grace [4] and Zheng and Zhang [13] investigated the influence of smooth and abrupt exit configuration in a bench-scale CFB unit. If blinded-T geometry was used, a cavity was formed between cyclone level and the projected roof. They concluded that a riser exit with suitably chosen geometrical design parameter, including the height of projected roof and the contracted exit area, could enhance the internal solids recycling. Hence prolong the residence time of fine char particles and would enhance heat transfer between wall and gas-solid flow in CFB combustor. 
The purpose of this study was to investigate the effect of abrupt exit geometry on the riser axial void fraction in a dilute regime above the upper transport velocity as defined by Monazam et al.[14] or fast fluidized regime. It is well known that there are radial voidage distributions in riser flow, especially in the core-annular regime. Even so, there is considerable value for the design engineer to have a simplified axial expression that can be used to predict average solids loading and subsequently required blower power.Based on an extensive experimental data using solid particle of different size and density in large scale CFB, a newanalysis is presented describing axial voidage profile near the riser exit. This analysis uses newly developed engineering expressions to define the boundary values for void fraction at the riser outlet and fully developed regions. The relationships are also used to predict the length of influence for an abrupt (T-shape) exit.

\section{Experimental}

A series of experiments were performed to study the effect of exit geometry on the riser axial voidage profile. The axial voidage profiles were obtained using time-averaged riser pressure profile measurements made in a large cold flow circulating fluidized bed (CFCFB). The test unit configuration is described by Monazam et al. [15] and shown in Figure 1. It consisted of a riser of $30.48 \mathrm{~cm}$ diameter and $16.65 \mathrm{~m}$ high. The solids enter the riser from a side port $0.23-\mathrm{m}$ in diameter and $0.27-\mathrm{m}$ above the gas distributor. Solids exit the riser through a $0.20-\mathrm{m}$ port at $90^{\circ}$ about $1.2-\mathrm{m}$ below the top of the riser at a point $15.45-\mathrm{m}$ above the solids entry location (centerline to centerline). Twenty incremental differential pressures were measured along the height of the riser using transmitters calibrated within $0.1 \%$ of full scale or about $2 \mathrm{~Pa} / \mathrm{m}$. The primary response measurement was the overall riser pressure differential and it was calibrated within 0.45 
$\mathrm{Pa} / \mathrm{m}$. Riser velocities were corrected for temperature and pressure as measured at the base of the riser. The air's relative humidity was maintained between 40 and $60 \%$ to minimize effects of static charge building up on the solids. Mass circulation rate was continuously recorded by measuring the rotational speed of a twisted spiral vane located in the packed region of the standpipe as described by Ludlow et al. [16].

The properties of the three solids are presented in Table 1. The cork material is quite light having a density of only $188 \mathrm{~kg} / \mathrm{m} 3$ with a relatively large particle size. It appears in the lower regions of the Geldart group A/B material (Figure 2) actually below the Geldart classification. The material behaves like a group B material. The coke and the glass beads are adjacent to each other on the Geldart map, with coke just above the $\mathrm{AB}$ demarcation line and glass beads just above it. The operating conditions for the tests are shown in Table 2. The cork and glass bead tests were conducted near atmospheric pressure whereas the coke tests were conducted at pressures between 200 and $300 \mathrm{kPa}$.

\section{Results and Discussions}

The pressure profiles are shown in Figure 3for a given gas velocity and different solids flux using cork, glass beads andcoke. The pressure profiles for all three materials are normalized to a pressure of zero at the riser exit.The riser pressure profile for the cork material is presented in Figure 3(a). The maximum pressure, for the case with the highest solids flux is about $1.8 \mathrm{kPa}$ as shown by the blue " $\mathrm{x}$ " at a height of $0 \mathrm{~m}$. The pressure drops rapidly form the bottom to the first port up the riser. The pressure then drops off linearly until a height of about $12 \mathrm{~m}$ and then drops fairly quicklyto zero at the exit $(16 \mathrm{~m})$ giving an overall S-shape to the curves. This shape is 
characteristic of a riser with three distinct regions: an acceleration region, a fully developed region and an exit region.

The glass bead data is shown in Figure 3b. This data id depicted by the same S-shape family of curves, only at a higher pressure. The densest case for a solids flux rate of $281.8 \mathrm{~kg} / \mathrm{m}^{2} \mathrm{~s}$ has the highest pressure of about $28 \mathrm{kPa}$. Again, from bottom to top, the pressure drops off rapidly over the first meter, falls more or less linearly to a height of $12 \mathrm{~m}$ or so and then drops rapidly to the exit pressure. The coke data,shown in Figure 2c., is somewhat different in that there is no large pressure loss at the bottom of the riser. The curves start off with a linear drop with height to a about $12 \mathrm{~m}$ or so and then have a sharp drop to the riser exit. This difference in behavior is likely attributed to a couple of possibilities. The first of these is that the data were taken at considerable higher pressure, about $300 \mathrm{kPa}$. This affects the density and viscosity and eventually the drag. Another possible cause for this is that the entrance geometry is somewhat different. The data for cork and glass beads was taken for a riser being fed with an L-valve whereas the coke data was taken using a loop seal to feed the solids.

In summary, it is apparent from both the literature and the data (Figure 3) that an abrupt exit configuration can lead to an increase of the solids concentration along upper sections of the riser. Figure 3 also shows that by increasing the solids flux the riser pressure drop increases for a constant gas velocity.

The solids concentration can be calculated from the axial pressure profile measurement along the riser. To evaluate the axial apparent voidage, the axial pressure profiles in Figure 3 were fitted to a 
$5^{\text {th }}$ order polynomial in height and then differentiated to obtain $(d P / d z)$. The axial apparent voidage was related to the pressure drop through the following expression by Louge [17]:

$$
\frac{d P}{d z}=\rho_{s}(1-\varepsilon) g
$$

The calculated apparent axial voidage profile along the riser is presented in Fig. 4 for different solids flux values at a given gas velocity for a glass beads, coke and cork. These profiles indicate the appearance of a C-shape voidage profile that is characteristic of the solid flow in the riser with strong exit restriction[5]. At the bottom of the riser low apparent voidage values are observed, which rapidly increase with increasing height to the point where voidage start to decrease again as it approach the top of the riser. At lower solid flux, the axial voidage become uniform along the bed height. As solid flux is increased, the solid particles begin to accumulate at the bottom of the riser before accelerating to fully developed regions. Similar to that at the entrance region, the distributions of low apparent voids concentration at exit region are also observed. The influence of exit is observed not only at the top, but fora considerable distance back down the riser $(\mathrm{H}=11.5 \mathrm{~m})$ for higher solid flux. Therefore, the distribution of apparent voidageat the exit region under highflux conditions is quite differentfrom that under low-flux conditions. Figure 4 also shows that the apparent voidage concentration at both entrance and exit regions are asymmetrical due to influence of entrance and exit structure.

The differences in the voidage profiles for the three materials are attributed to the high operating pressure that the coke data set was taken at. Both Figure $4 \mathrm{~b}$ (cork) and Figure $4 \mathrm{c}$ (glass beads) have a very axisymmetric profile where the top is appears to be a reflection about the $8 \mathrm{~m}$ level. The coke data have a much longer entrance region (reduced fully developed region) extending all the way to the beginning of the exit region for the case with the highest solids flux. 


\section{Entrance Region}

The acceleration zone was characterized by Monazam et al. [18] using non-dimensional analysis of the gas and solid phases mass and momentum balances that described multiphase flows. This resulted in the engineering correlations for the voidage at the riser inlet (Equation 2) and the length of the acceleration zone (Equation 3). These correlations are shown in Figures 5 and 6 along with the respective data and $95 \%$ confidence intervals. The statistical range of the coefficients and exponents in these two correlations (Equation 2 and 3) can be found in Monazam et al. [18].

$$
\begin{gathered}
\varepsilon_{b}=1.0-0.005 \cdot\left(\frac{U_{s}}{U_{g}}\right)^{1.045}\left(\frac{D}{d_{p}}\right)^{0.541}\left(\frac{\rho_{g} U_{g} d_{p}}{\mu_{g}}\right)^{0.915} \\
\frac{L_{a c c}}{D}=3.225\left(\frac{U_{g}^{2}}{g D}\right)^{-0.351}\left(\frac{G_{s}}{\rho_{g} U_{g}}\right)^{0.22}\left(\frac{\rho_{s}-\rho_{g}}{\rho_{g}}\right)^{-0.94}\left(\frac{D}{d_{p}}\right)^{0.88}\left(\operatorname{Re}_{g}\right)^{0.304}
\end{gathered}
$$

\section{Fully Developed Region}

The fully developed zone is the region of the riser where the voidage remains constant. In this region the velocity of the gas and solids are relatively constant with variations in riser height. There are a few correlations in open literature for the prediction of the voidage in the fully developed region [18-23]. Monazam et al. [18] developed the following correlation to predict the void fraction in fully developed region of the riser:

$$
\varepsilon_{F D}=1-2.39 E-6\left(\frac{U_{g}^{2}}{g D}\right)^{-1.35}\left(\frac{G_{s}}{\rho_{g} U_{g}}\right)^{1.191}\left(\frac{\rho_{s}-\rho_{g}}{\rho_{g}}\right)^{0.562}\left(\frac{\rho_{g} U_{g} d_{p}}{\mu_{g}}\right)^{1.614}
$$


The statistical range of the coefficient and exponents in Equation 4 can be found in Monazam et al. [18].Figure 8 compare the experimental void fraction in fully developed region with the predicted voidage using Eq.4. Agreement is very good with variance explained, $\mathrm{R}^{2}>93 \%$.

\section{Exit Region}

The analysis considers the exit zone of the riser that can be significantly affected by exit geometry. According to Grace's [2] review on T-exit geometry at the top of the riser, acts as a crude gas-solid separator. As a result, the particles reflect the top and recirculate internally down along the wall of the riser. Therefore, it is assumed that the drag force results in the solids velocities gradient that is proportional to the velocity difference between solids in the exit zone and those below the exit zone of the riser as;

$$
\frac{d u_{s}}{d z}=k\left(u_{s \infty}-u_{s}\right)
$$

The decay constant, $k$, incorporates contributions of the gas and solids friction to the drag. The solids-wall and gas-wall friction were assumed to be insignificant as supported by the observation by Knowlton et al. [24] that wall friction becomes small with larger diameter vessels.

For one dimensional flow, the continuity equation for the solid phase reduced to

$$
\frac{d}{d z}\left[\rho_{s}(1-\varepsilon) u_{s}\right]=0
$$

Differentiating eqn. (5) yields

$$
\frac{d u_{s}}{d z}=-\frac{u_{s}}{1-\varepsilon} \frac{d(1-\varepsilon)}{d z}
$$

Considering $G_{s}=\rho_{s}(1-\varepsilon) u_{s}=\rho_{s}\left(1-\varepsilon_{\infty}\right) u_{s \infty}$, combining eqns. (4) and (6) yields 


$$
\frac{d \varepsilon}{d z}=\frac{k(1-\varepsilon)\left(\varepsilon_{\infty}-\varepsilon\right)}{\left(1-\varepsilon_{\infty}\right)}
$$

The solution of eqn. (7) requires the knowledge of $k, \varepsilon_{\infty}$, and an initial voidage condition specified at any one location in the riser.

In this study, to solve eqn. (7) it is assumed the voidage at $z=0$ is the voidage at the top of the riser, $\varepsilon_{\text {exit }}$, and $\varepsilon_{\infty}$ is the fully developed voidage, $\varepsilon_{F D}$. Thus, Eqn. (7)can be integrated directly to:

$$
\frac{\left(\varepsilon-\varepsilon_{F D}\right)\left(\varepsilon_{e x i t}-1\right)}{\left(\varepsilon_{e x i t}-\varepsilon_{F D}\right)(\varepsilon-1)}=e^{-k z}
$$

To simplify Eq. 8 the ratio, $\frac{\varepsilon_{e x i t}-1}{\varepsilon-1}$, and the exponential factor, $k$, were combined to calculate a new effective exponential factor, $K_{\text {decay. }}$. Then eqn. (8) simplified to:

$$
\frac{\varepsilon_{L_{\text {end }}}-\varepsilon_{F D}}{\varepsilon_{\text {exit }}-\varepsilon_{F D}}=e^{-K_{\text {decary }} z}
$$

Where $\varepsilon_{\text {Lend }}$ is the apparent voidage profile for length of influence duo to abrupt exit geometry, $\varepsilon_{\text {exit }}$ is the voidage at the exit of the riser, $\varepsilon_{F D}$ is the voidage for the fully developed region and $K_{\text {decay }}$ is the rate constant. The new exponential constant, $K_{\text {decay }}$ is an apparent decay factor different from that in Eq. 8. In Eq 9 the values for $\varepsilon_{\text {Lend }}$ approaches $\varepsilon_{F D}$ for large $\mathrm{z}$ and $\mathrm{d} \varepsilon / \mathrm{dz}=0$. The value for $\varepsilon_{\text {exit }}$ is the maximum voidage constraint at $\mathrm{z}=0$, and when $\mathrm{z}>0$ the resulting values for $\varepsilon_{F D}$ and $K_{\text {decay }}$ become greater than 0 . The value for $\varepsilon_{F D}$ is the voidage at its asymptotic limit. When $\mathrm{z}$ approaches 0 then $\varepsilon_{a p p}$ approaches $\varepsilon_{\text {exit }}$. 
Using the axial voidage profile (Fig. 3) and Eq. (9), $K_{\text {decay }}$ and the length of influence (Lend)can be obtained. The length of influence is defined from the exit of the riser to the point where fully developed flow has finished. The fully developed zone is the region of the riser where voidage remain constant. A sample of comparison between the axial voidage profile using Eq. (4) and axial voidage profile obtained using Eq. (9) for the exit region is illustrated in Fig. 4. Agreement is very good over the entire exit region with variance explained $>99.5 \%$.

In the present study, a series of steady state experiments was conducted to characterize the internal flow behavior of a riser in a dilute regime. The solid materials used for this study were cork, coke, and glass beads. The characteristics of each of the three bed materials tested are presented in Table 1. The cork was the lightest and the coarsest particle used, the glass beads were smallest and densest, and coke was intermediate in both respect. Over 75 steady state data sets were obtained spanning a range of gas velocities (3.5-13 m/s), pressures (1 to 3 atmospheres), and solids recirculation rate $\left(1-540 \mathrm{~kg} / \mathrm{m}^{2}-\mathrm{s}\right)$. A series of dimensionless parameters are known to ensure hydrodynamic similitude in analysis of these data sets when scaling circulating fluid beds [24-26]. These scaling parametersrepresenta non-dimensionalization of the continuum equations that describe multiphase flows as derived by Anderson and Jackson [27]. Dimensionless parameters included were Froud number, load ratio, density ratio, Reynolds number; as well as diameter ratio and Archimedes. The Froude number $\left(\frac{U_{g}^{2}}{g D}\right)$ varied from 0.5-39, load ratio $\left(\frac{G_{s}}{\rho_{g} U_{g}}\right)$ from 0.2-28, density ratio $\left(\frac{\rho_{s}-\rho_{g}}{\rho_{g}}\right)$ from 138-1381, Reynold number $\left(\frac{\rho_{g} U_{g} d_{p}}{\mu_{g}}\right)$ from 8-600 and Archimedes number (Ar) from 29-3600. Using a wide pool of experimental dilute data, empirical expressions for the voidage at the exit of the riser, length of influence, and the voidage for the fully developed 
region were developed. Multiple regression analyses were conducted using a stepwise approach to maximize the variance explained. Those parameters which did not contribute significantly to the variance explained were discarded.

The voidage at the exit of the riser was determined using the voidage at the outlet ofthe axial voidage profile (Fig. 3). In trying to find a reliable and more general correlation for $\varepsilon_{\text {exit }}$, various dimensionless groups that might give unified representation of the experimental data were tested. The following empirical correlation for predicting the voidage at the exit of the riser as a function of particle properties and operating conditions was obtained.

$$
\varepsilon_{\text {exit }}=1.0-2.38 E-3\left(\frac{G_{s}}{\rho_{g} U_{g}}\right)^{0.917}\left(\frac{\rho_{s}-\rho_{g}}{\rho_{g}}\right)^{-1.041}\left(\frac{D}{d_{p}}\right)^{0.704}\left(\operatorname{Re}_{g}\right)^{0.901}
$$

The coefficients were taken as the average of the upper and lower limits for the $95 \%$ confidence limits. The coefficients are $2.38 \mathrm{E}-3 \pm 0.002,0.917 \pm 0.081,-1.041 \pm 0.175,0.704 \pm 0.165$, and $0.901 \pm 0.11$, for each term respectively. As a result, Eq. 11 could be simplified within the statistical significance of the data such that the exponent on the $1^{\text {st }}, 2^{\text {nd }}$ and $4^{\text {th }}$ term could be considered unity. However, if this is done, then care must be taken to evaluate whether the terms yield consistent units when the dimensionless groups are broken down, and the variability of each of the terms should be comparable or the result could generate a bias not found in the original data. The comparison between the experimental data on the exit voidage $\left(\varepsilon_{\text {exit }}\right)$ and the predicted of Eq. (11) is illustrated in Fig. 5. Agreement is good with variance explain $\left(\mathrm{R}^{2}\right)$ of $87 \%$. The apparent voidage at the exit of the riser had a nearly linear dependence upon load ratio and $R e$ number. This dependence suggest that the apparent voidage at the exit lack of overall dependence on the superficial gas velocity. 
There are only a few empirical correlations available in the literatures that predict the length of influence of the CFB riser. Harris et al. [8] developed an correlation that relate the ratio of length of influence to the height of the riser to the Froud number, Archimedes number, $d_{p} / D, L_{\text {riser }} / D$, Reynolds Number, and the solids to fluid loading ratio.

In this study, the following correlation was developed to predict the length of influence in the dilute regime:

$$
\frac{L_{\text {end }}}{D}=9.73\left(\frac{U_{g}^{2}}{g D}\right)^{-0.45}\left(\frac{G_{s}}{\rho_{g} U_{g}}\right)^{-0.123}\left(\frac{\rho_{s}-\rho_{g}}{\rho_{g}}\right)^{-1.75}\left(\frac{D}{d_{p}}\right)^{1.77}
$$

Like in Eq. 11 the coefficients were taken as the average of the upper and lower limits for the 95\% confidence limits. The coefficients are $9.73 \pm 2.86,-0.45 \pm 0.071,-0.123 \pm 0.059,-1.75 \pm 0.794$, and $1.77 \pm 0.267$ for each term, respectively. The length of influence was dependent on the Fr, load ratio, density and diameter ratios. The density and diameter ratios were the strongest factors determining the length of influence. The influence length was inversely related to both solids density and size; the larger the particle density and diameter the shorter the length of influence. This might be expected since the larger and denser particles exhibit greater slip than the smaller or lighter particles and thus travel a shorter length before the drag force offsets the gravitational force.

Figure 6 show how the experimental length of influence compares with the predicted length of influence based on Eq. 12. The coefficient of multiple variations is 0.73 indicating that $73 \%$ of the regression data is described by Eq. 12. This equation provides an easy procedure for evaluating the effect of length of influence on the hydrodynamic of the riser. 
As a further test of the quality of the correlations (Equations 11 and 12), the cross correlation matrix for the independent variables in each of these correlations for the voidage at the top of the riser and the length of the exit region are shown in Table 3 and Table 4 . The general rule of thumb, the cross correlation coefficient should lie between -0.7 and 0.7 to eliminate standard error estimates associated with the collinearity of the independent variables [28]. Our data set contains three cross correlation coefficients that are slightly outside this rule of thumb. The largest of these is the correlation between the density ratio $\left\{\left(\rho_{\mathrm{p}}-\rho_{\mathrm{g}}\right) / \rho \mathrm{g}\right\}$ and the ratio of the riser diameter to the particle size $\{\mathrm{D} / \mathrm{dp}\}$ with a value of 0.744 - only $6 \%$ outside the 0.7 value from the rule of thumb. Thererfore, it is important to include both of these variables in the analysis even though there is a slight possibility of collinearity as these are important hydrodynamic variables in multiphase flow and that the range of these variables exceeds an order of magnitude. The density ratio ranges from 138 to 1381 and the diameter ratio ranges from 375 to 5000 . These ratios do track together in most riser flow cases; equipment physical constraints limit the use of large particles to particles with lower density. Additionally, since this equipment related constraint is more or less universal to all systems, both parameters should be included.

The cross correlation value of the density ratio to the Reynolds number is slightly less than that for the density ratio and the diameter ratio as can be seen in Table 3. Again, there is value in including the Reynolds number as it is an extremely important parameter in fluid mechanics and is varied in the analysis by more than an order of magnitude. This is also true for the density ratio and the load ratio. 
The rate constant, $K_{\text {decay }}$, in Eq. 7 was related to the length of influence using following equation:

$$
K_{\text {decay }}=4.0 L_{\text {end }}^{-1.04}
$$

Figure 7 shows the comparison between experimentally determined, $K_{\text {decay }}$, and calculated using Eq. 13. Agreement is very good with variance explained, $\mathrm{R}^{2}>95 \%$.

\section{Evaluation of Riser Pressure Profile Relationships}

The relationships developed above and in the earlier work by Monazam et al.[14] are tested below to evaluate the applicability of the relationships to other materials and operating conditions. The relationships for the volume fraction and the entrance length, developed using cork and $60 \mathrm{um}$ glass beads, are evaluated for 188 um glass beads operating in or near the dense suspension upflow (DSU) operating regime, coke operating at pressure and at conditions that approached DSU and for PPE that had an Archimedes number of 15800 and at very high gas velocities in or near the DSU regime are presented in Figures 12 and 13. Examination of Figure 12 shows that the correlation for the voidage at the bottom of the riser is quite robust extending the operating space to include the Geldart Group A coke and the Geldart group B 188 um glass beads regardless of the operating regime. The correlation breaks down for the PPE material, over predicting the voidage. The correlation for the voidage at the bottom of the rise was not found to be a function of the Fraud number or the density ratio that when combined with the Reynolds number can give the Archimedes number which is about 5 times value for the cork and more than 15 times the value for the 60 um glass beads. Therefore, the applicability of the correlation is limited to materials with Archimedes numbers less than about 4000. 
The entrance length predictions for the three data sets noted in the above paragraph are compared with the correlation predicting it in Figure 13. The correlation is not applicable for operation near or in the DSU regime where the entrance length is significantly under predicted. It is also not applicable for materials having a large Archimedes number.

The correlation for the fully developed voidage is compared to the 188 um glass bead and PPE materials described above and to the pressurized operation of the riser with coke in figure 14 . The voidage for the data set for the pressurized coke operation is clearly under predicted. The correlation is independent of the pressure, where the contributions from the contributions from the Reynolds number, loading ratio and density ratio combine to cancel out any effect of pressure. Also, the voidage for the DSU conditions for the 188 um glass bead data is also under predicted. The majority of the data set for the PPE material falls outside the $95 \%$ confidence interval of the correlation, again limiting the application of the correlation to materials with Archimedes numbers less than 4000 .

The correlations for the top of the riser are compared to the 188 um glass bead and PPE data sets in Figures 15 and 16. The voidage at the top of the riser is over predicted for the DSU 188 um glass bead and PPE data as can be seen in Figure 15. It is not surprising that the DSU data is not predicted as the correlation is independent of gas velocity and DSU only occurs when the gas velocity is high enough to carry the solids up without back mixing. The exit length correlation is compared with the data sets in Figure 16. The 188 um glass bead clearly do not fit the correlation limiting the correlations useful range to conditions that do not include DSU. The same is true for the PPE material although the data falls within the $95 \%$ confidence interval. It is, however, 
significantly outside the range the correlation was developed for and without a Reynolds number effect in the correlation, the Archimedes number is not considered. Therefore, even though the data fall with in the 95\% confidence interval, applying the correlation to materials with an Archimedes number greater than about 4000 can lead to significant errors.

\section{Conclusion}

An extensive experimental and theoretical investigation was carried out to determine the T-outlet effects in riser of cold flow circulating fluidized bed on the gas-solid suspension density. The experimental results obtained from over 75 sets of operating conditions in the regimes above fast fluidization. The data sets were spanning a range of gas velocities $(3.5-13 \mathrm{~m} / \mathrm{s})$, pressures ( 1 to 3 atmospheres), and solids recirculation rate $\left(1-450 \mathrm{~kg} / \mathrm{m}^{2}-\mathrm{s}\right)$. The solid materials used for this study were cork, coke, and glass beads. The cork was the lightest $\left(\rho_{\mathrm{s}}=189 \mathrm{~kg} / \mathrm{m}^{3}\right)$ and the coarsest particle $\left(d_{p}=812 \mu \mathrm{m}\right)$ used, the glass beads were smallest $\left(d_{p}=60 \mu \mathrm{m}\right)$ and densest $\left(\rho_{\mathrm{s}}=2500 \mathrm{~kg} / \mathrm{m}^{3}\right)$, and coke was intermediate in both respect $\left(230 \mu \mathrm{m}\right.$ and $\left.1250 \mathrm{~kg} / \mathrm{m}^{3}\right)$. The theoretical expression was derived from a drag relationship and momentum equations to describe the gas-solids profile in the vicinity of the riser exit with a T-outlet. The riser pressure profile was analyzed and results or the solids fraction at the top of the riser and the fully developed regions, were used to define the boundary conditions to solve the theoretical expression. In addition, the test data was analyzed to evaluate the deceleration length duo to abrupt exit,and, in turn, the decay constant. The deceleration length was related to gas and solid velocity,and even more strongly related to solids density and particle size. The voidage at the exit of the riser was linearly related to solid flux and the relative density of the gas and solids. These engineering expressions can be used as a tool for 
simulation and design of the riser of CFB and also can be easily coupled to kinetics model for process simulation.

The riser pressure profile relations developed herein and in earlier work by Monazam et al. [14] are valid for materials other than those used in the development of the correlations provided that they are applied to materials within the state space defined by the following dimensionless groupings: Fr (0.5-39), Re (8-600), Ar (29-3600), load ratio (0.2-28), riser to particle diameter ratio (375-5000), and gas to solids density ratio (138-1381). There is wide discrepancy in the predicted parameters for Archimedes numbers exceeding the 3600 value used in the development of the relationships. Additionally, application of the relationships outside the regime bounded by operation above the upper transport velocity on the low side and below DSU will likely lead to under predicting the entrance length, the fully developed voidage and the exit length while over predicting the voidage at the top of the riser. 


$\begin{array}{ll}\text { Notation } & \\ D & \text { riser diameter }(\mathrm{m}) \\ d_{p} & \text { particle size }(\mu \mathrm{m}) \\ g & \text { acceleration due to gravity }\left(\mathrm{m}^{2} / \mathrm{s}\right) \\ G_{s} & \text { solids flux }\left(\mathrm{kg} / \mathrm{m}^{2} \mathrm{~s}\right) \\ K_{\text {decay }} & \text { decay constant }\left(\mathrm{m}^{-1}\right) \\ L_{\text {end }} & \text { length of influence due to exit geometry }(\mathrm{m}) \\ P & \text { pressure }(\mathrm{kPa}) \\ R_{g} & \text { Reynolds number } \\ U_{g} & \text { superficial gas velocity }(\mathrm{m} / \mathrm{s}) \\ z & \text { vertical coordinate }(\mathrm{m})\end{array}$

\section{Greek letters}

$\varepsilon \quad$ voidage

$\varepsilon_{\text {exit }} \quad$ voidageat the exit of riser

$\varepsilon_{F D} \quad$ voidage in the fully developed region

$\varepsilon_{\text {Lend }} \quad$ voidage along the length of influence

$\mu_{g} \quad$ gas viscosity $(\mathrm{g} / \mathrm{cm} \mathrm{s})$

$\rho_{g} \quad$ gas density $(\mathrm{g} / \mathrm{cc})$

$\rho_{s} \quad$ solid density $(\mathrm{g} / \mathrm{cc})$ 


\section{Acknowledgment}

The authors acknowledge the Department of Energy for funding the research through the Fossil Energy’s Integrated Gasification Combined Cycle program.

\section{Disclaimer}

The U.S. Department of Energy, NETL and REM contributions to this report was prepared as an account of work sponsored by an agency of the United States Government. Neither the United States Government nor any agency thereof, nor any of their employees, makes any warranty, express or implied, or assumes any legal liability or responsibility for the accuracy, completeness, or usefulness of any information, apparatus, product, or process disclosed, or represents that its use would not infringe privately owned rights. Reference herein to any specific commercial product, process, or service by trade name, trademark, manufacturer, or otherwise does not necessarily constitute or imply its endorsement, recommendation, or favoring by the United States Government or any agency thereof. The views and opinions of authors expressed herein do not necessarily state or reflect those of the United States Government or any agency thereof.

The authors declare no competing financial interest.

\section{References}

1. Wen, C. Y., Chen, L. H., 1983. Flow modeling of fluidized beds, in: N.P. Cheremisinoff, R. Gupta (Eds.), The Handbook of Fluids in Motion, Ann Arbor, Michigan, 665-714.

2. Grace, J. R., 1996. Riser geometry influence on CFB particle and fluid dynamics. in Fifth International Conference on Circulating Fluidized Bed Technology. Beijing, China, PL2 116. 
3. Senior,R. C., 1992. Circulating fluidized bed fluid and particle mechanics: Modeling and experimental studies with application to combustion. PhD Thesis, University of British Columbia, Vancouver, Canada.

4. Brereton, C. M. H., Grace,J. R., 1994. End effects in circulating fluidized bed hydrodynamics,in: A. A. Avidan (Eds). Circulating Fluidized Bed Technology IV, Hidden Valley, PA., 137-144.

5. Lim, K. S., Zhu, J. X., Grace,J. R.,1995. Hydrodynamics of gas-solid fluidization, Int. J. Multiphase Flow, 21(Suppl.), 141.

6. Zhang, R., Yang, H., Wu, Y., Zhang, H., Lu, J. Experimental study of exit effect on gassolid flow and heat transfer inside CFB risers. Exp. Therm. and Fluid Sci. 2013, 51, 291296.

7. Mabrouk, R., Chaouki, J. Guy C. Exit effect on hydrodynamics of the internal circulating fluidized bed riser. Powder Technol. 2008, 182, 406-414.

8. Harris, A. T., Davidson, J. F., Thorpe,R. B., 2003. Influence of exit geometry in circulating fluidized-bed risers. AIChE J. 49, 52-64.

9. Pugsley,T., Lapointe, D., Hirschberg, B., Werther,J.,1997. Exit effects in circulating fluidized beds riser. Can. J. Chem. Eng. 75, 1001-1010

10. Vanengelandt, G., Heynderickx, G.J., DeWilde, Juray, Marin, G.B. Experimental and computational study of T- and L-outlet effects in dilute riser flow. Chem. Eng. Sci. 2011, $66,5024-5044$.

11. Kim, Jun-Sik, Tachino, R., Tsutsumi, A. Effects of solids feeder and riser exit configuration on establishing high density circulating fluidized beds. Powder Technol. $2008,187,37-45$. 
12. Jin, Y., Yu, C., Qi, C., Bai, D., 1988. The influence of exit structures on the axial distribution of voidage in a fast fluidized bed. In: M. Kwauk, D. Kunii (Eds.) Fluidization 88, Science and Technology, Science Press, Beijing, 165-173.

13. Zheng, Q., Zhang, H., 1994. Experimental study of the effect of bed exits with different geometric structure on internal recycling of bed material in CFB boilers. In: A. A. Avidan (Eds). Circulating Fluidized Bed Technology IV, Hidden Valley, PA., 145-151.

14. Monazam, E.R., Shadle, L.J., Mei, J., Spenik, J., 2005. Identification and characteristics of different flow regimes in a circulating fluidized bed, Powder Technology, 155, 17-25, 2005.

15. Monazam, E.R.,Shadle, L. J. andLawson, L. O.,A transient method for determination of saturation carrying capacity, Powder Technology, Volume 121, Issues 2-3, 26 November 2001, Pages 205-212

16. Ludlow, J. C., Lawson, L. O., Shadle, L. J., and Syamlal, M., Development of a spiral device for measuring the solids flow in a circulating fluidized bed, in Circulating Fluidized Bed Technology VII, Grace, J. R., Zhu, J., de Lasa, H., Eds., Canadian Society of Chemical Engineering: Ottawa, Canada, 2002, p 513.

17. Louge, M, Change, H. Pressure and voidage gradients in vertical gas-solid risers. Powder Technol. 1990, 60, 197.

18. Monazam, E.R.,Shadle, L. J., Analysis of the acceleration region in a CFB riser operating above fast fluidization velocities"Ind.\& Eng. Chem. Res., 47, 8423-8429, 2008

19. Kunii, D., Levenspiel, O. Fluidization Engineering, 2nd ed., Butterworth-Heinemann: Oxford, U.K., 1991. 
20. Patience, G. S., Chaouki, J., Berruti, F., Wong, R. Scaling considerations for circulating fluidized bed risers. Powder Technol. 1992, 72, 31.

21. Quyang, S., Potter, O. E. Consistency of circulating fluidized bed experimental data. Ind. Eng. Chem. Res. 1993, 32, 1041.

22. Bai, D., Kato, K. Quantitative estimation of solids holdups at dense and dilute regions of circulating fluidized beds. Powder Technol. 1999, 101, 183.

23. Lee, DH., Lee, H. S., Lim, J. H., Park, S. S., Chae, H. J., Jeong, S. Y., Decay factor with experimental variables in two circulating fluidized bed (CFN) risers, The $13^{\text {th }}$ International Conference on Fluidization, 2010, http://dc.engconfintl.org/fluidization_xiii/54

24. Knowlton, T. M, Carson, J. W, Klinzing, G. W, Yang, Y-C. Particle technology-the importance of storage, transfer, and collection. Chem. Eng.Prog. 1994, 90, 44.Horio, M., Ishii, H., Kobukai, Y., Yamanishi, N. A scaling lawfor circulating fluidized beds. J. Chem. Eng. Jpn. 1989, 22, 587.

25. Chang, H., Louge, M. Fluid dynamic similarity of circulatingfluidized beds. Powder Technol. 1992, 70, 259.

26. Glicksman, L. R., Hyre, M. R., Farrell, P. A. Dynamic similarityin fluidization. Int. J. Multiphase Flow. 1994, 20, 331.

27. Anderson, T. B., Jackson, R. A. Fluid mechanical description offluidized beds. I\&EC Fundam. 1967, 6, 527.

28. Lind, D.A., Marchal, W. G. and Wathen, S. A., "Statisticsl Techniques in Business and Economics, McGraw-Hill Irwin, Boston, 2005. 
Table 1 Material Properties

\begin{tabular}{|l|l|l|l|}
\hline Material & Cork & Coke & Glass Beads \\
\hline Density $\left(\mathrm{kg} / \mathrm{m}^{3}\right)$ & 189 & 1250 & 2550 \\
\hline Particle Size $(\mu \mathrm{m})$ & 812 & 230 & 60 \\
\hline Sphericity $(-)$ & 0.84 & 0.85 & 0.90 \\
\hline D/dp (-) & 375 & 1325 & 5000 \\
\hline Ar $(-)$ & 3593 & 608 & 868 \\
\hline Geldart classification & B/A & B & A \\
\hline
\end{tabular}


Table 2 Operating Condition Ranges

\begin{tabular}{|l|l|l|l|}
\hline Material & Cork & Coke & Glass Beads \\
\hline $\mathrm{P}(\mathrm{kPa})$ & 100.5 to 115.5 & 200 to 300 & 151.3 to 153.7 \\
\hline$(\rho \mathrm{s}-\rho \mathrm{g}) / \rho \mathrm{gg}(-)$ & 138 to 159 & 617 to 822 & 153 to 1381 \\
\hline$\rho \mathrm{g}\left(\mathrm{kg} / \mathrm{m}^{3}\right)$ & 1.18 to 1.36 & 1.70 to 2.26 & 1.18 to 1.79 \\
\hline $\operatorname{Re}(-)$ & 203.3 to 599.4 & 83.3 to 118.5 & 37 to 304 \\
\hline Fr $(-)$ & 4.84 to 39.52 & 4.94 to 9.77 & 4.8 to 39.1 \\
\hline Gs/G (-) & 0.22 to 3.24 & 0.62 to 9.33 & 0.2 to 28.00 \\
\hline Configuration & Loop seal & Loop seal & L-valve \\
\hline
\end{tabular}


Table 3. Cross Correlation Matrix for Exit Voidage Relationship

\begin{tabular}{|l|r|r|r|l|}
\hline & $\mathbf{G}_{\mathbf{s}} / \mathbf{G}$ & $\left(\rho_{\mathrm{p}}-\rho_{\mathrm{g}}\right) / \rho_{\mathrm{g}}$ & $\mathrm{D} / \mathbf{d}_{\mathrm{p}}$ & $\mathrm{Re}$ \\
\hline $\mathbf{G}_{\mathbf{S}} / \mathbf{G}$ & $\mathbf{1}$ & & & \\
\hline$\left(\rho_{\mathrm{p}}-\rho_{\mathrm{g}}\right) / \rho_{\mathrm{g}}$ & 0.739 & 1 & & \\
\hline $\mathbf{D} / \mathbf{d}_{\mathrm{p}}$ & 0.474 & 0.744 & 1 & \\
\hline $\operatorname{Re}$ & 0.514 & 0.740 & 0.522 & 1 \\
\hline
\end{tabular}


Table 4. Cross Correlation Matrix for Exit Length Relationship

\begin{tabular}{|l|r|r|r|r|}
\hline & \multicolumn{1}{|l|}{ Fr } & \multicolumn{1}{|l|}{$\mathbf{G}_{\mathbf{s}} / \mathbf{G}$} & $\left(\rho_{\mathrm{p}}-\rho_{\mathrm{g}}\right) / \rho_{\mathrm{g}}$ & \multicolumn{1}{l|}{$\mathbf{D} / \mathbf{d}_{\mathrm{p}}$} \\
\hline $\mathbf{F r}$ & 1 & & & \\
\hline $\mathbf{G}_{\mathbf{s}} / \mathbf{G}$ & 0.169 & 1 & & \\
\hline$\left(\rho_{\mathrm{p}}-\rho_{\mathrm{g}}\right) / \rho_{\mathrm{g}}$ & 0.106 & 0.739 & 1 & \\
\hline $\mathbf{D} / \mathbf{d}_{\mathrm{p}}$ & 0.015 & 0.474 & 0.744 & 1 \\
\hline
\end{tabular}




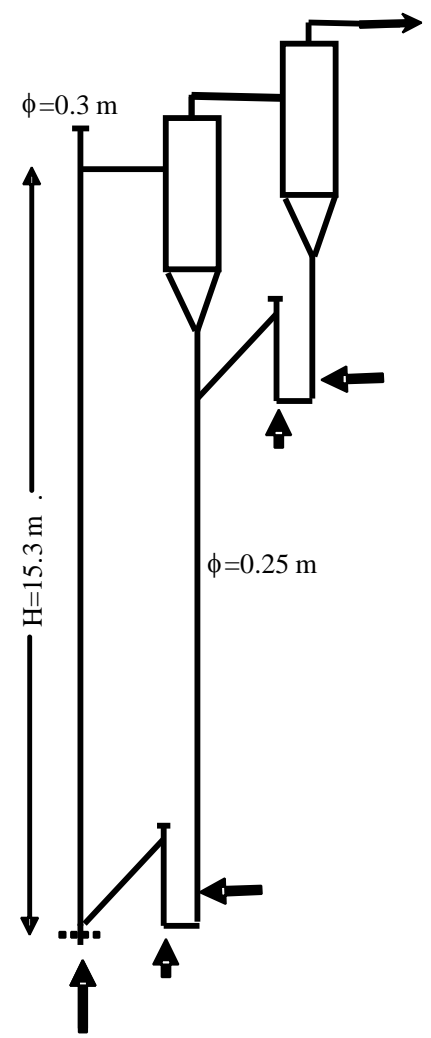

(a) Loop Seal

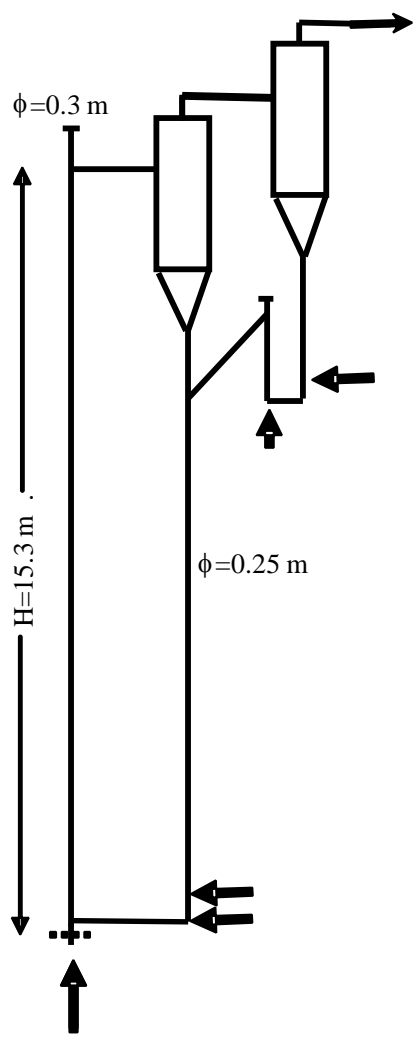

(b) L-Valve

Figure 1 Schematic of CFB with the loopseal solids return loop and $T$-shape riser exit. 


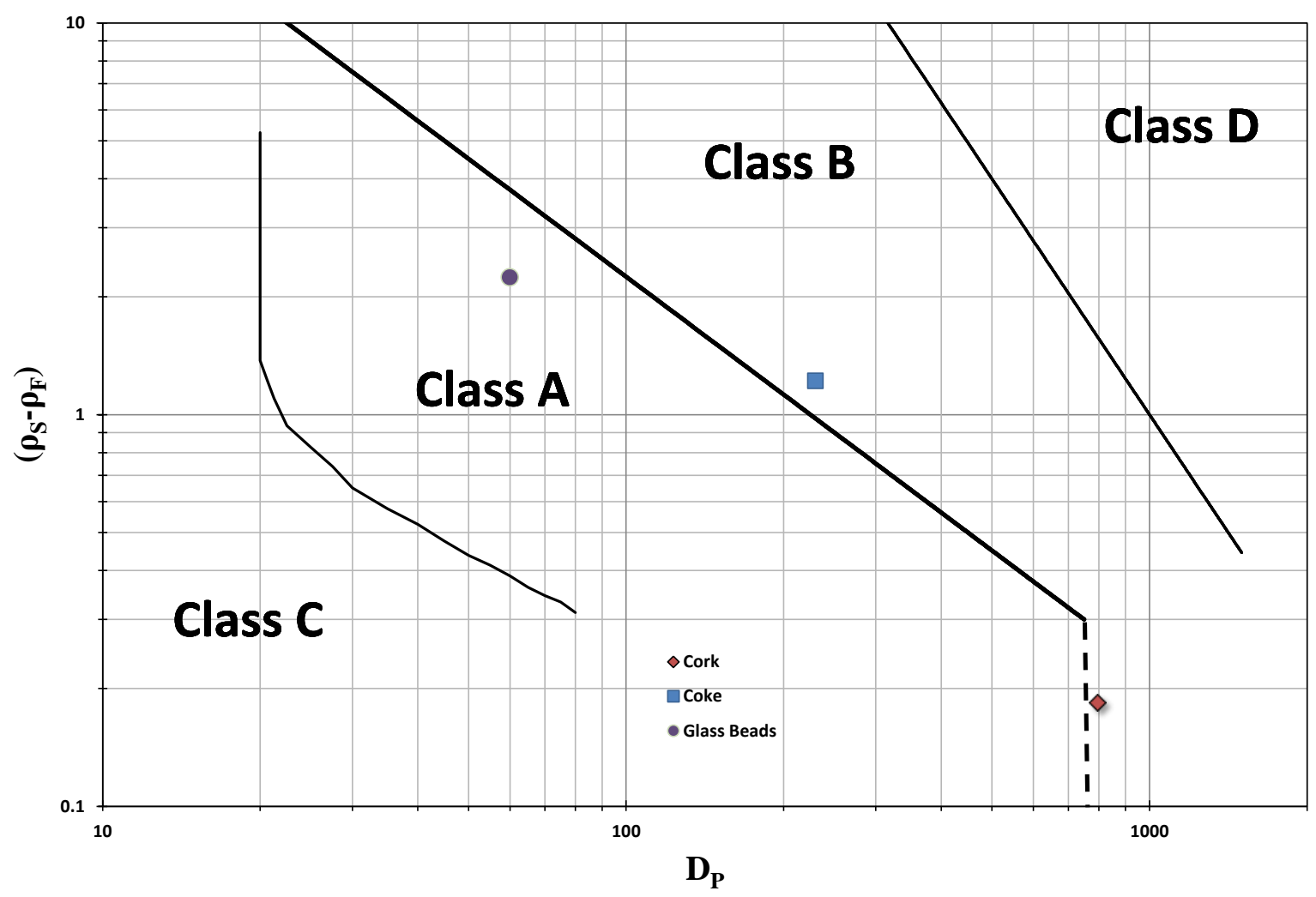

Figure 2. Geldart Particle classification. 


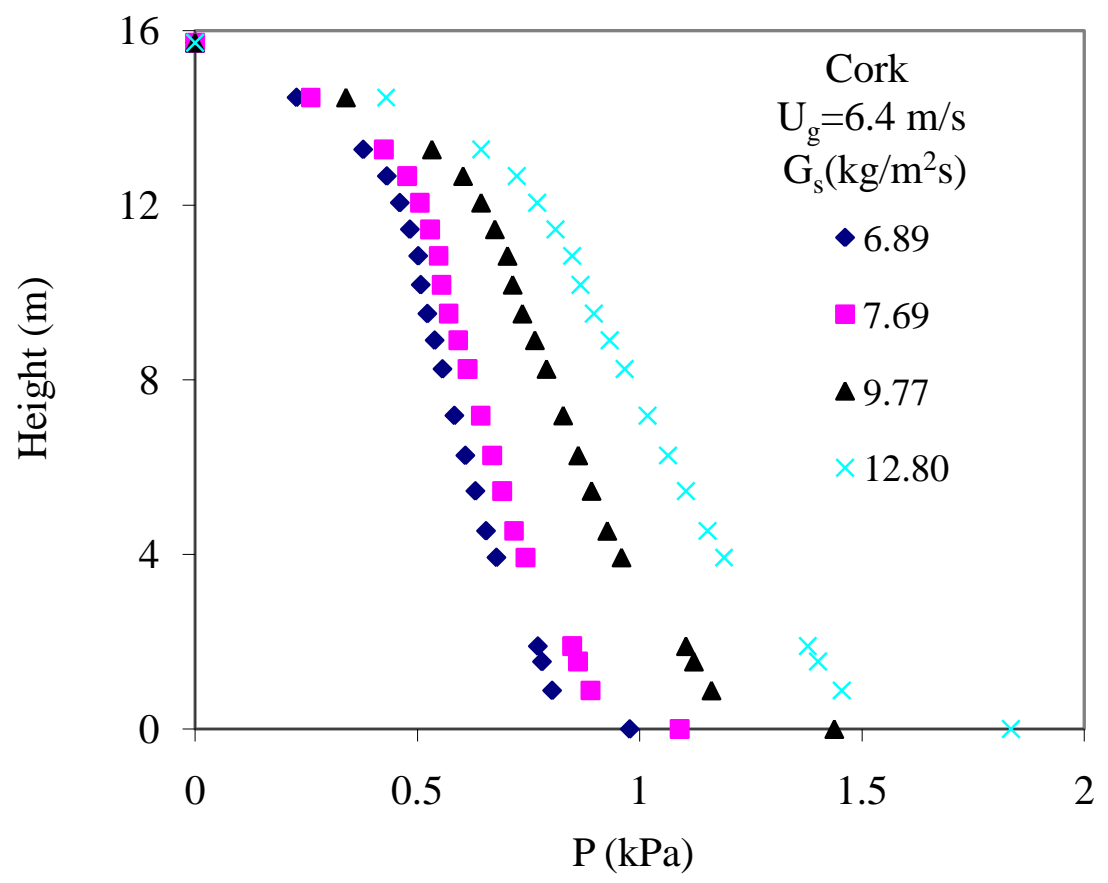



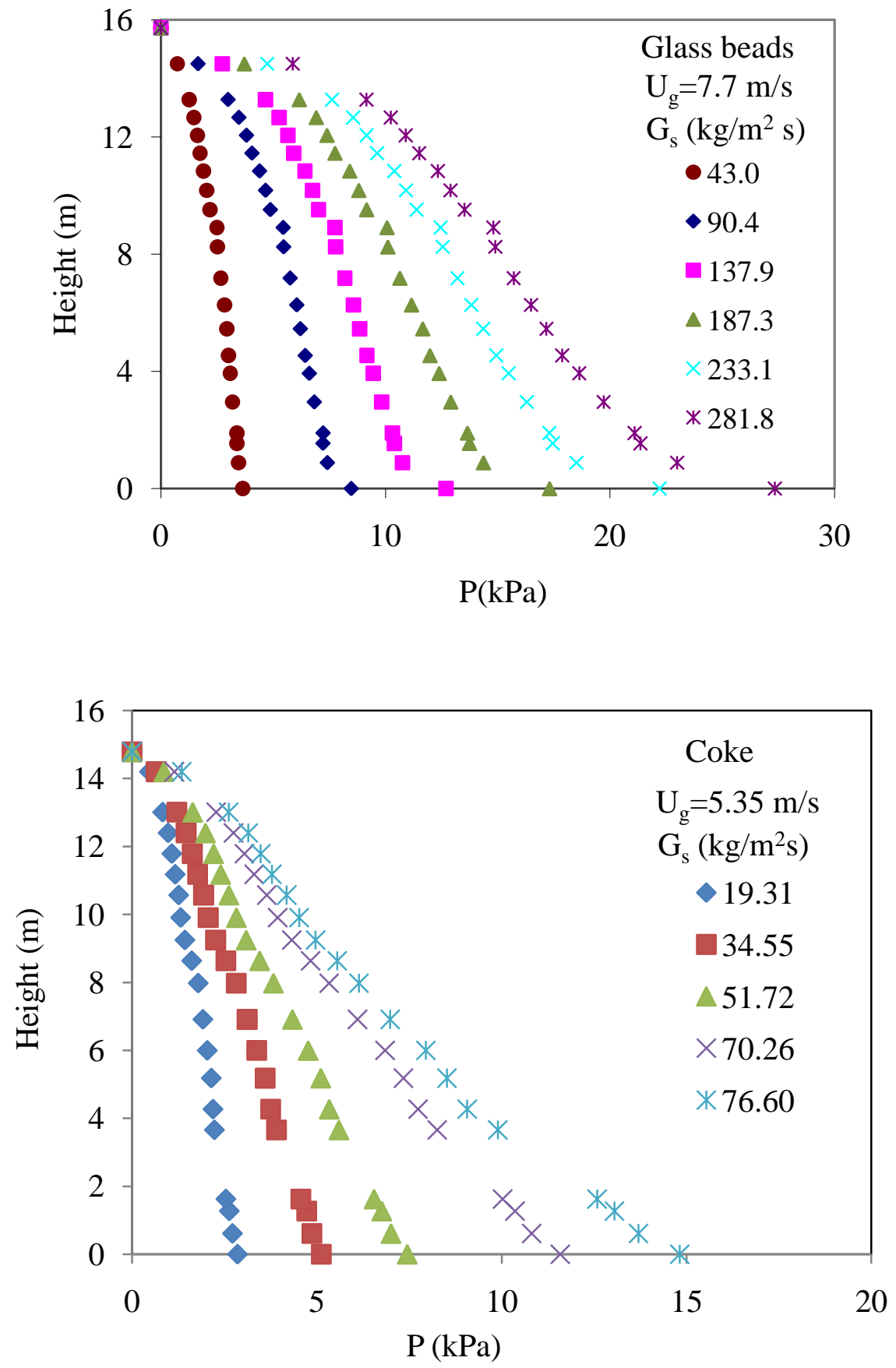

Figure 3. Pressure profile along the height of the riser for cork, glass beads and coke over a range of solids fluxes for specified gas velocities. 

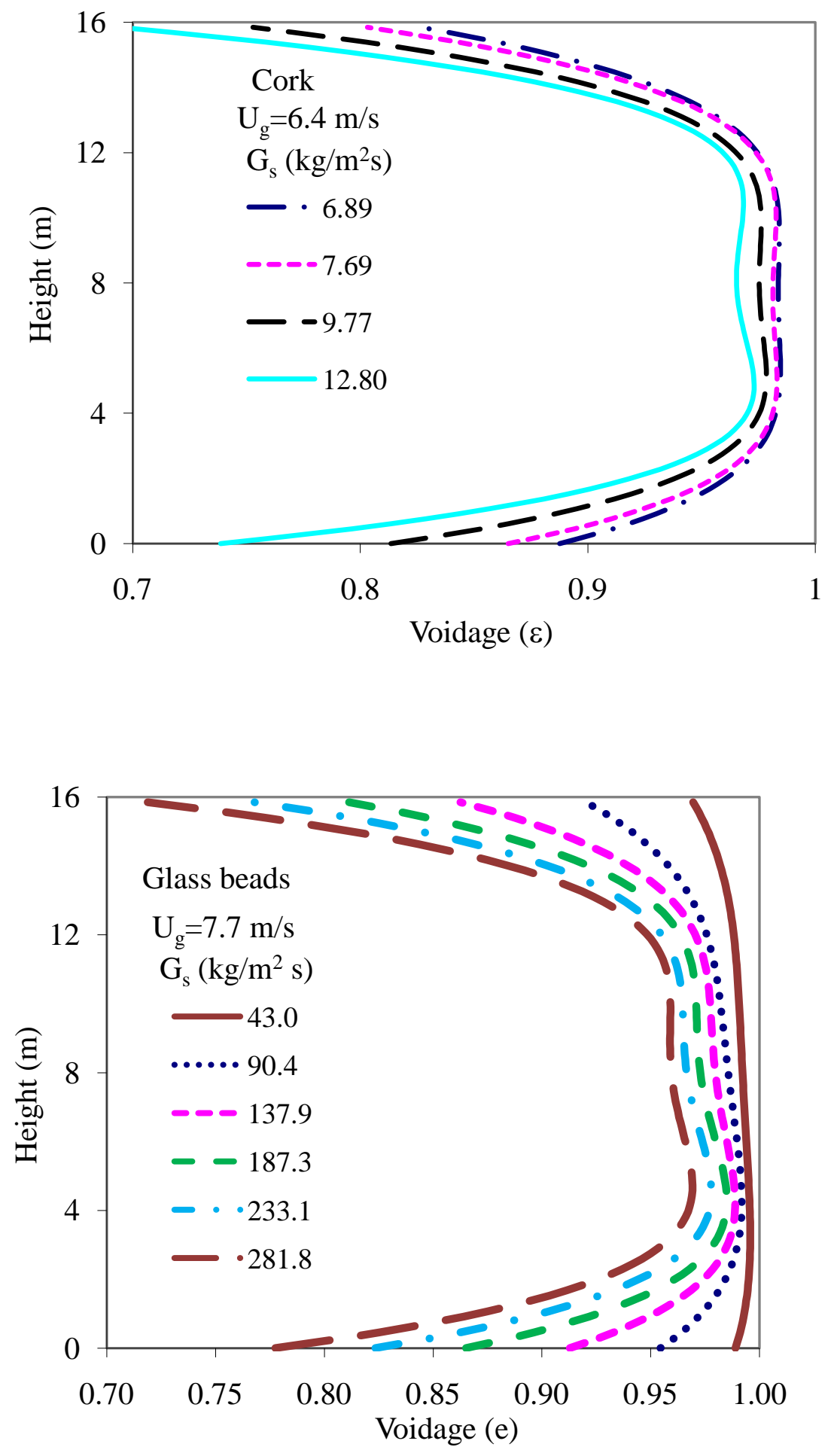


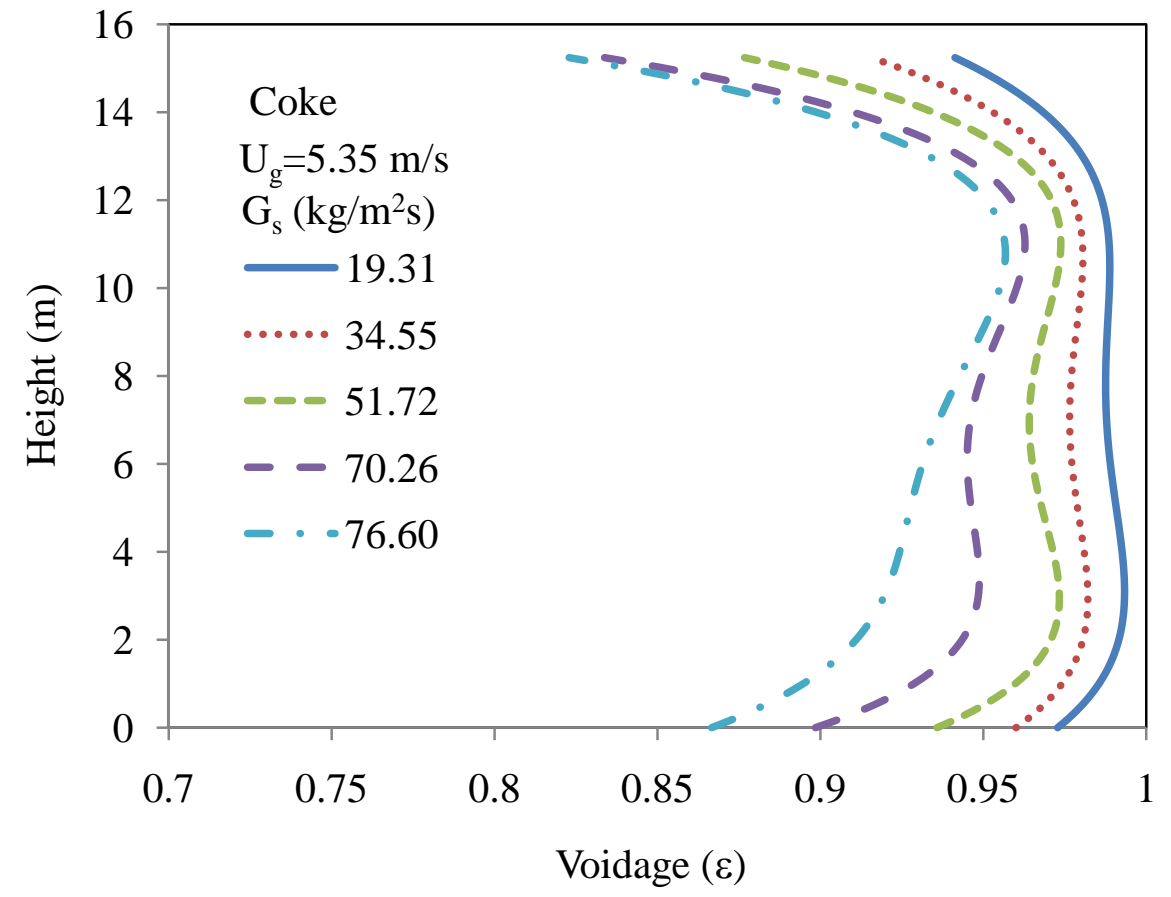

Figure 4.Axial voidage profile for glass beads for cork, glass beads and coke over a range of solids fluxes for specified gas velocities. 


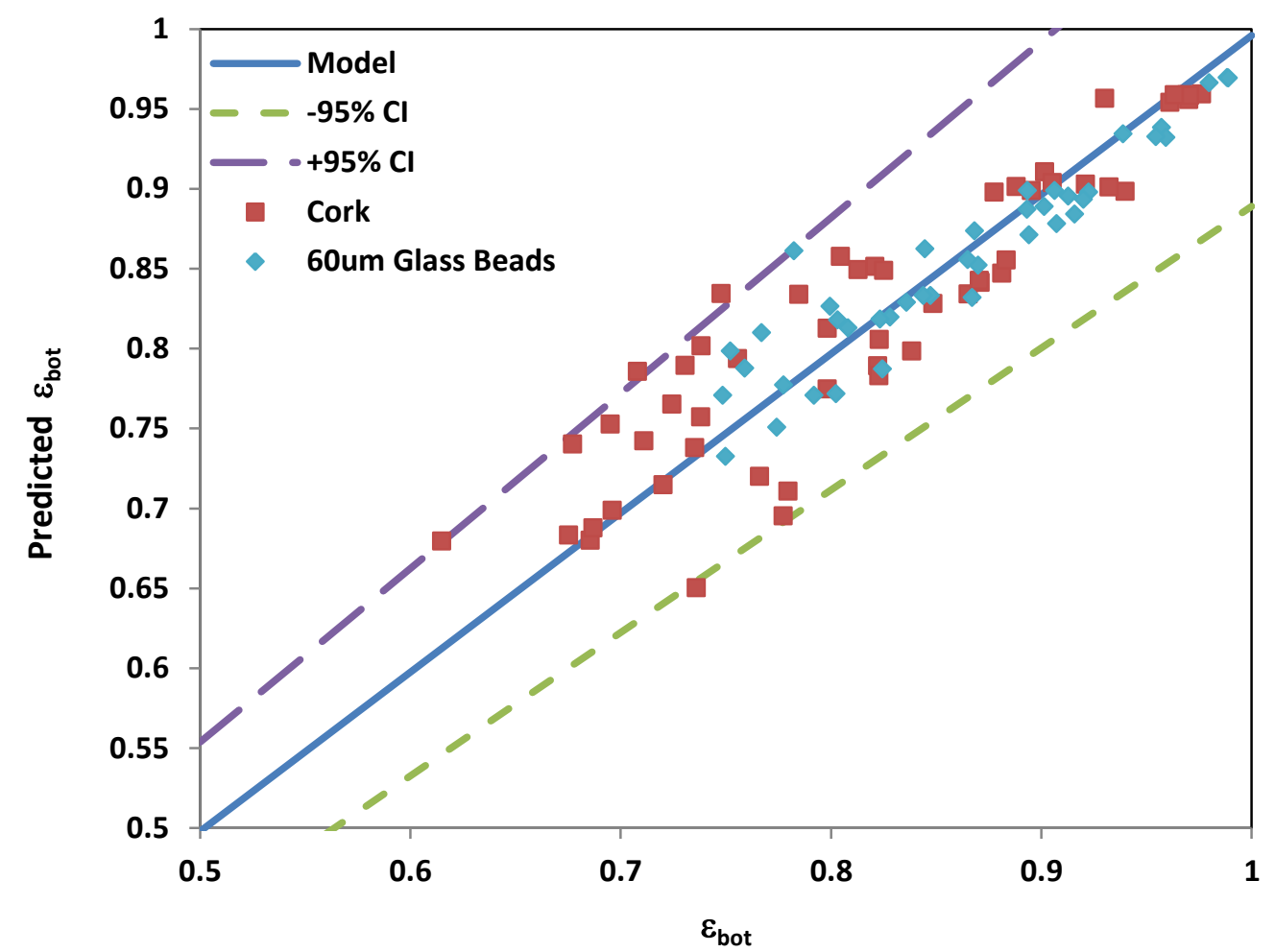

Figure 5 Bottom voidage 


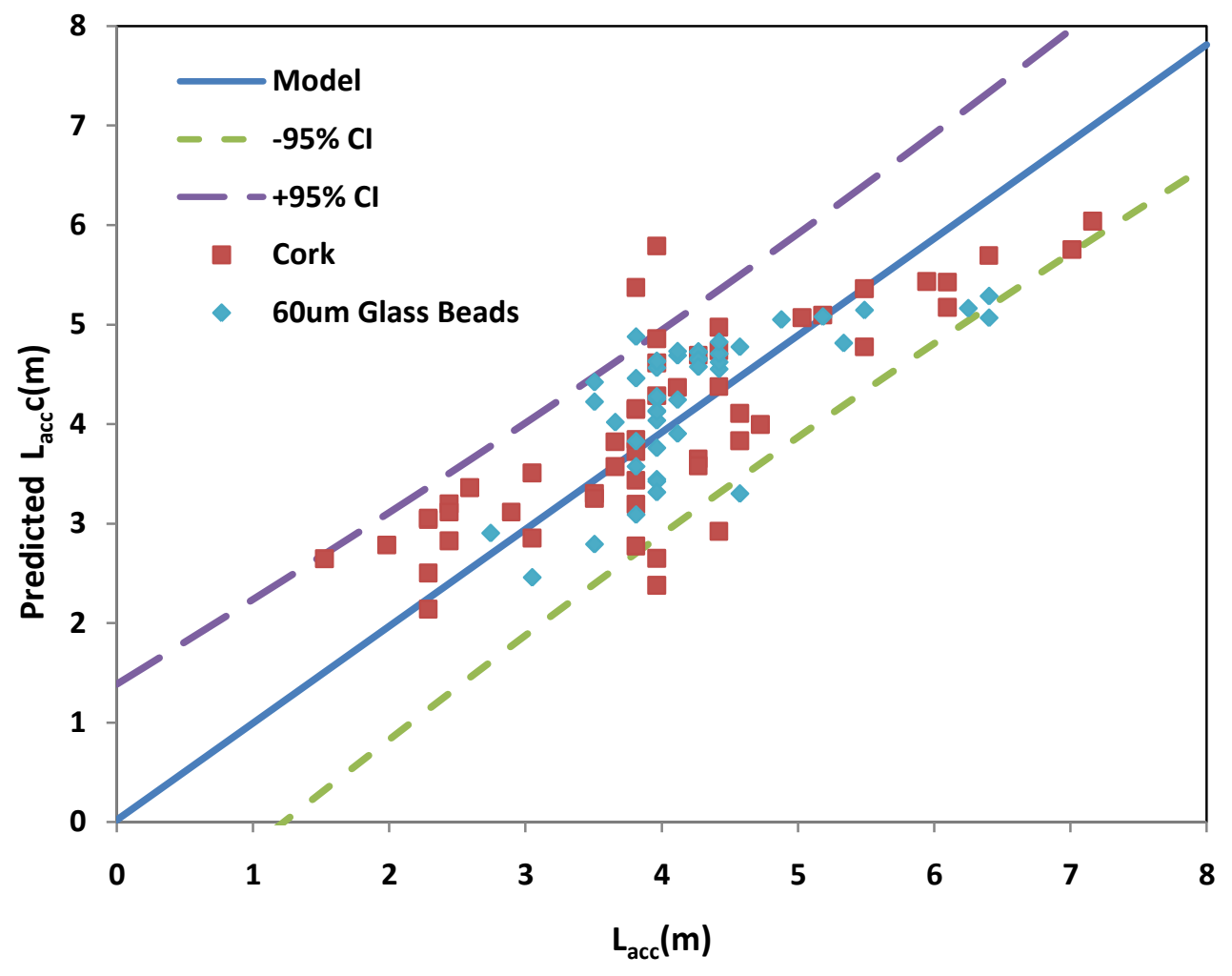

Figure 6 Entrance length 


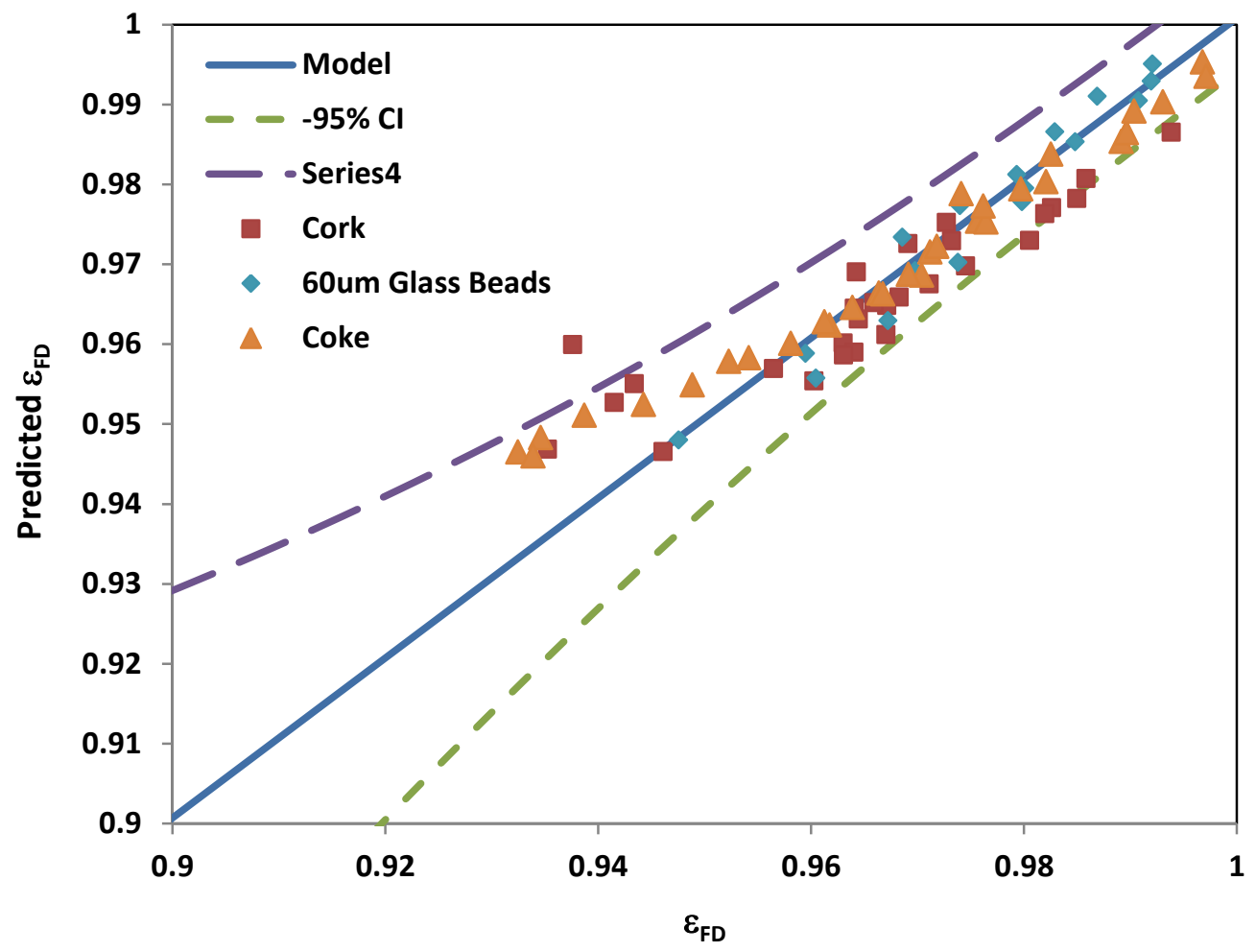

Figure 7 voidage fully developed 


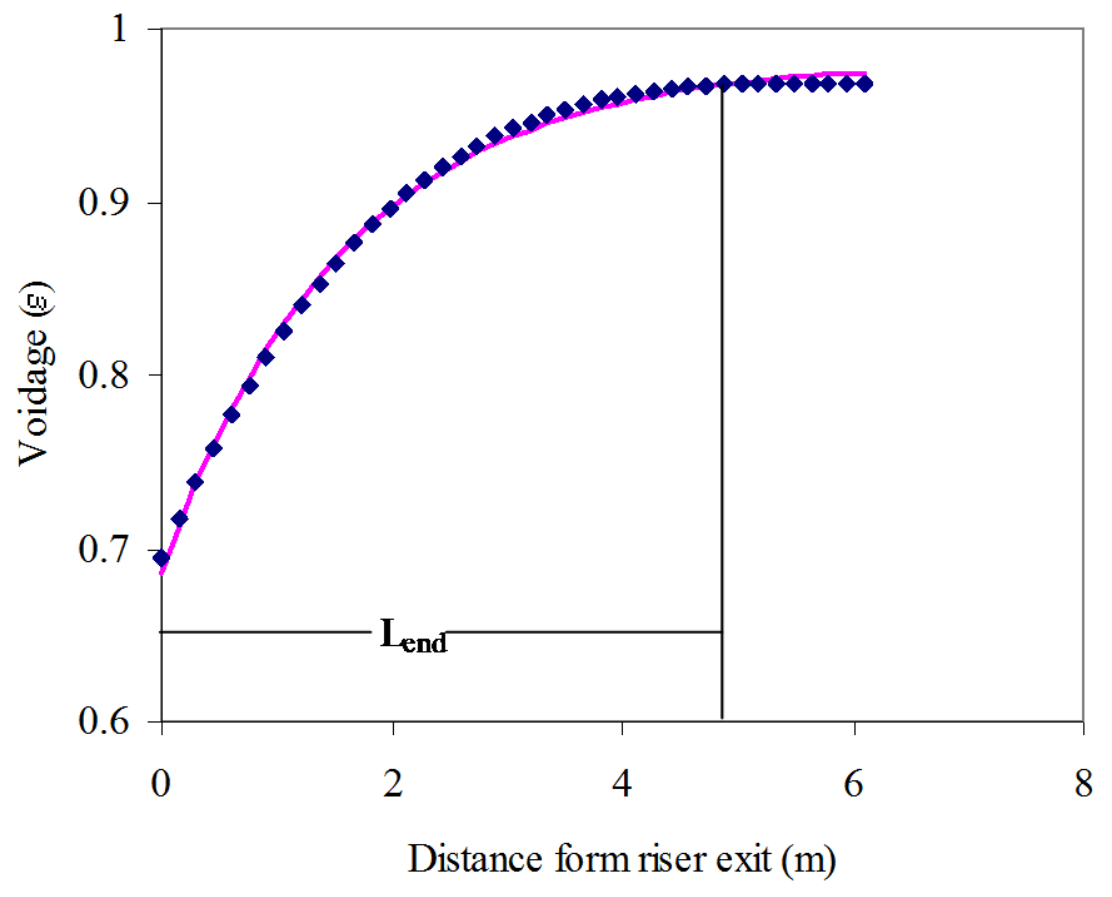

Figure 8 Apparent voidage profile near the top of the riser for a typical operating condition comparing experimental data from Fig. 2 (symbols) and correlation Eq. (7) (solid line). Cork test at $6.36 \mathrm{~m} / \mathrm{s}$ and $12.8 \mathrm{~kg} / \mathrm{m}^{2} \mathrm{~s}$. 


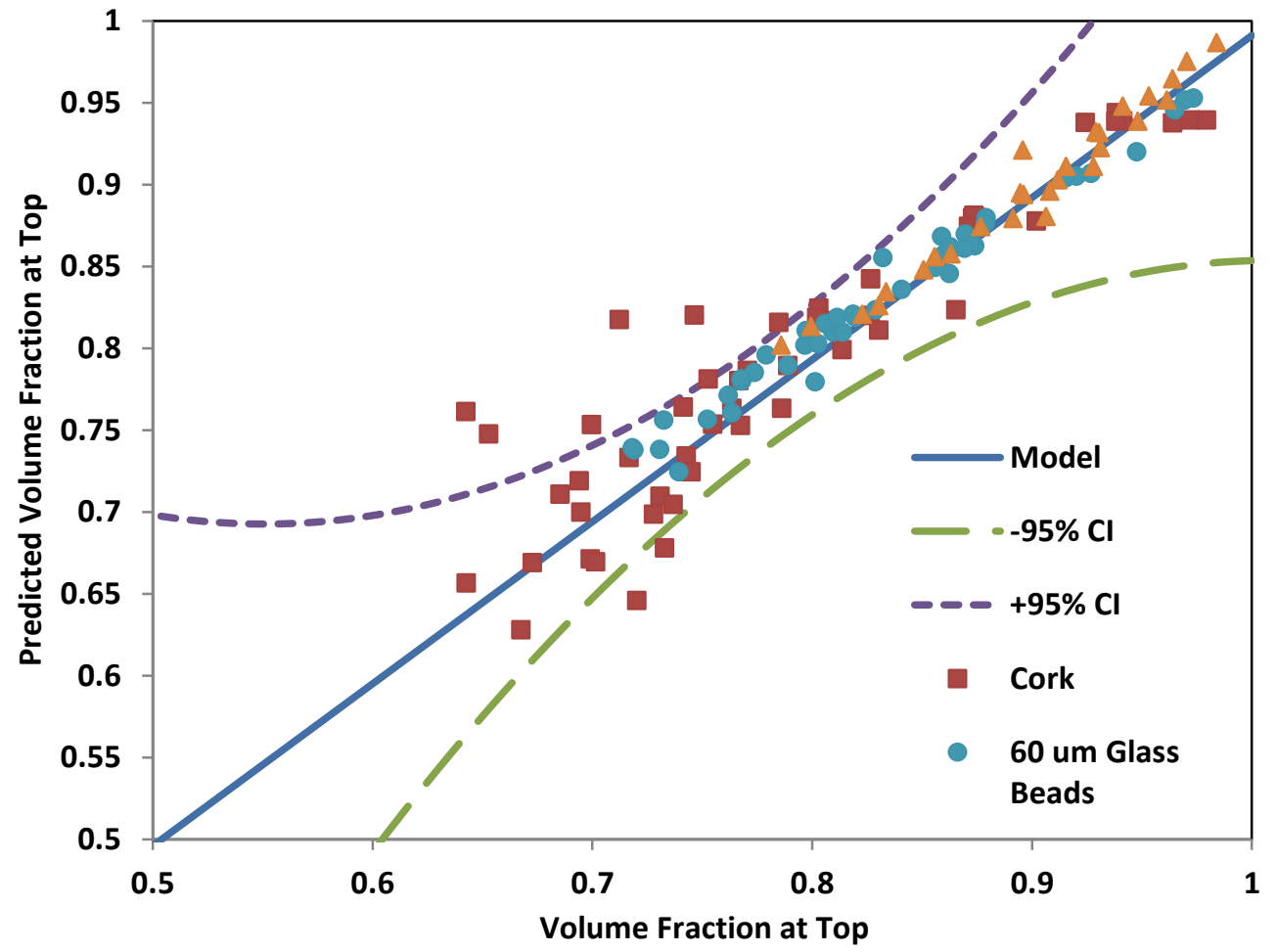

Figure 9 Comparison of predicted and experimental voidage at the riser exit for all test conditions. 


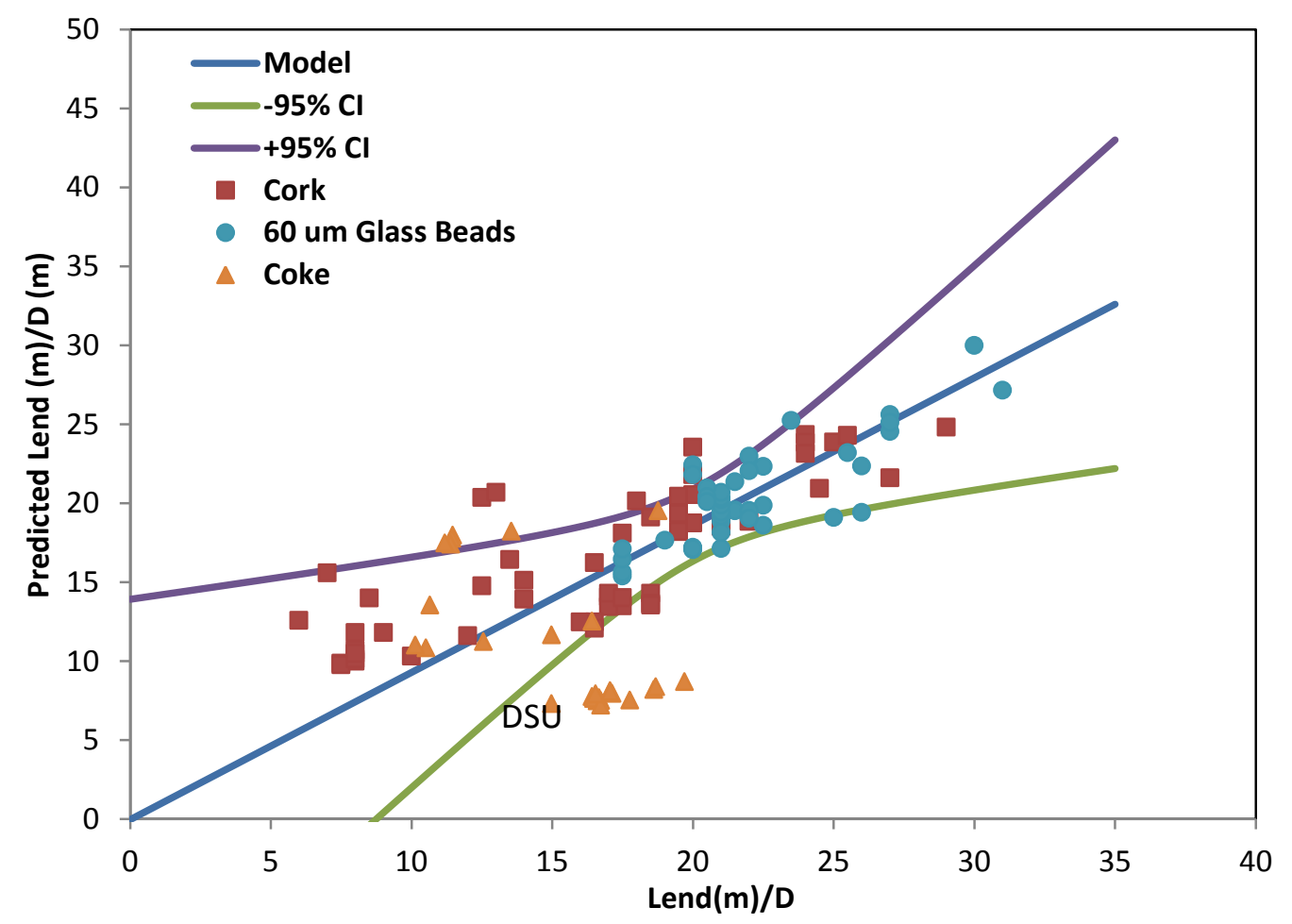

Figure 10 Comparison of the experimental and predicted length of influence at the top of the riser for all test conditions. 


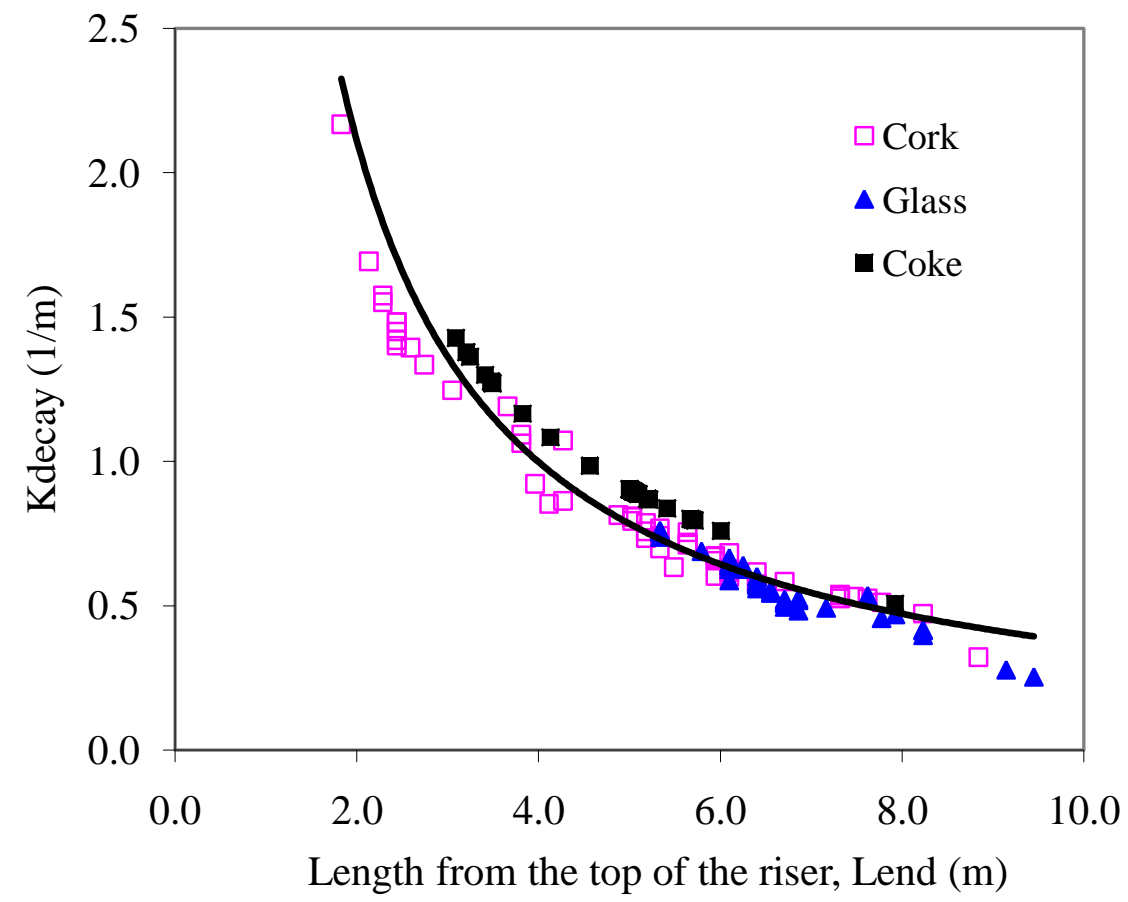

Figure 11 The exponential decay constant for the void fraction at the top of the riser for all test conditions; experimental test data (symbols) and predicted values using Eq. (6) (solid line). 


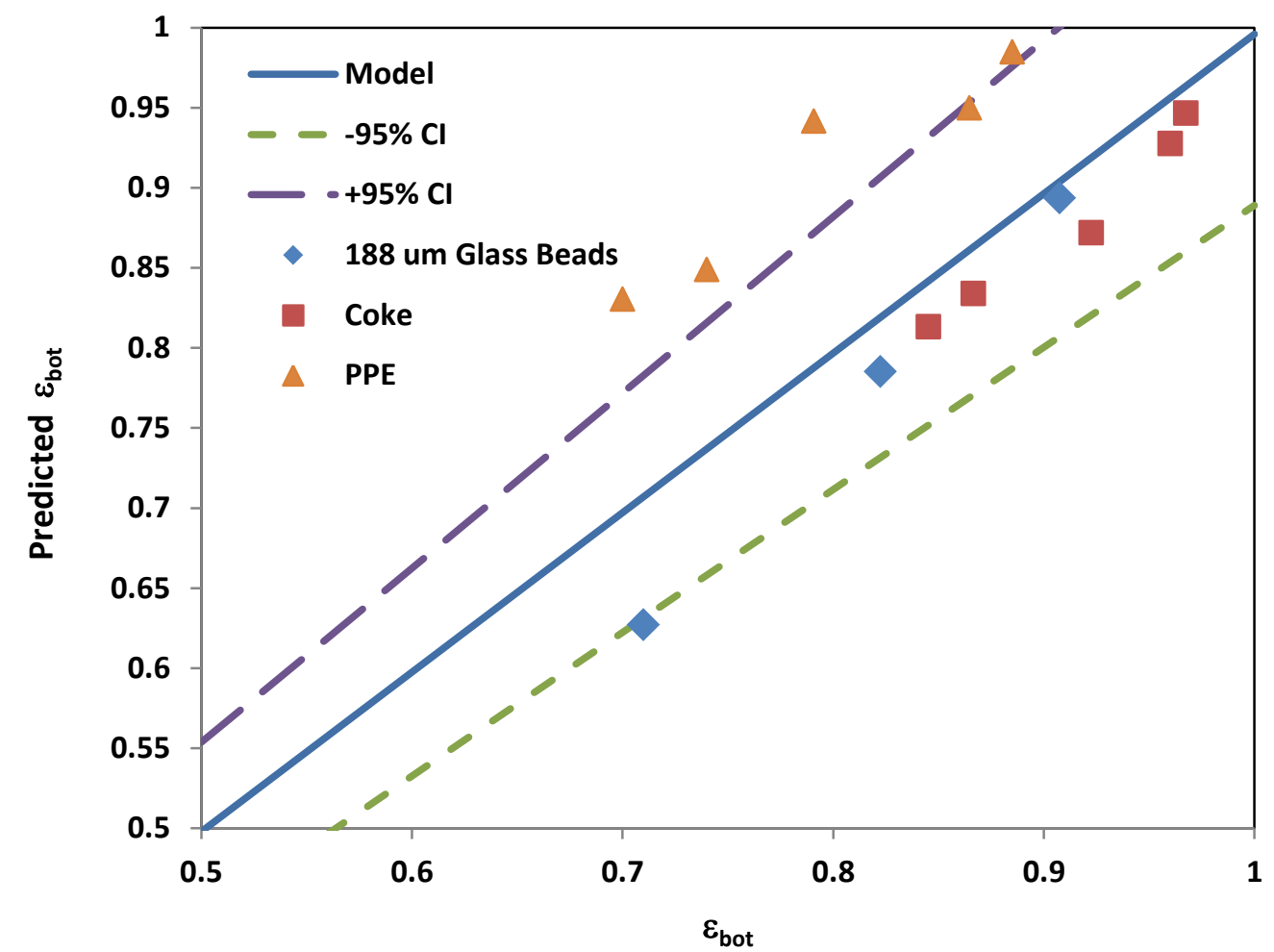

Figure 12. Bottom voidage extended data set 


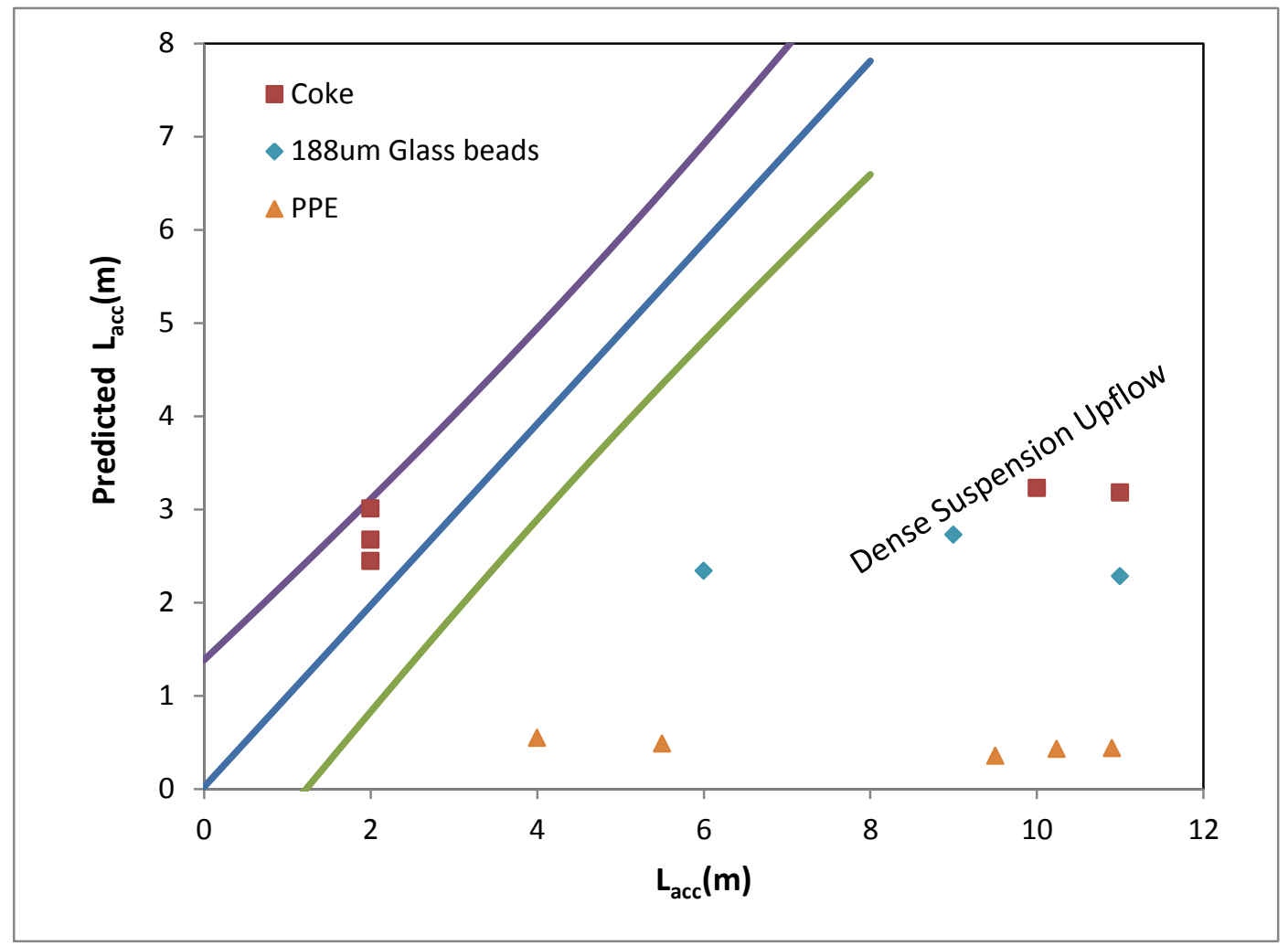

Figure 13. Entry Length extended data sets 


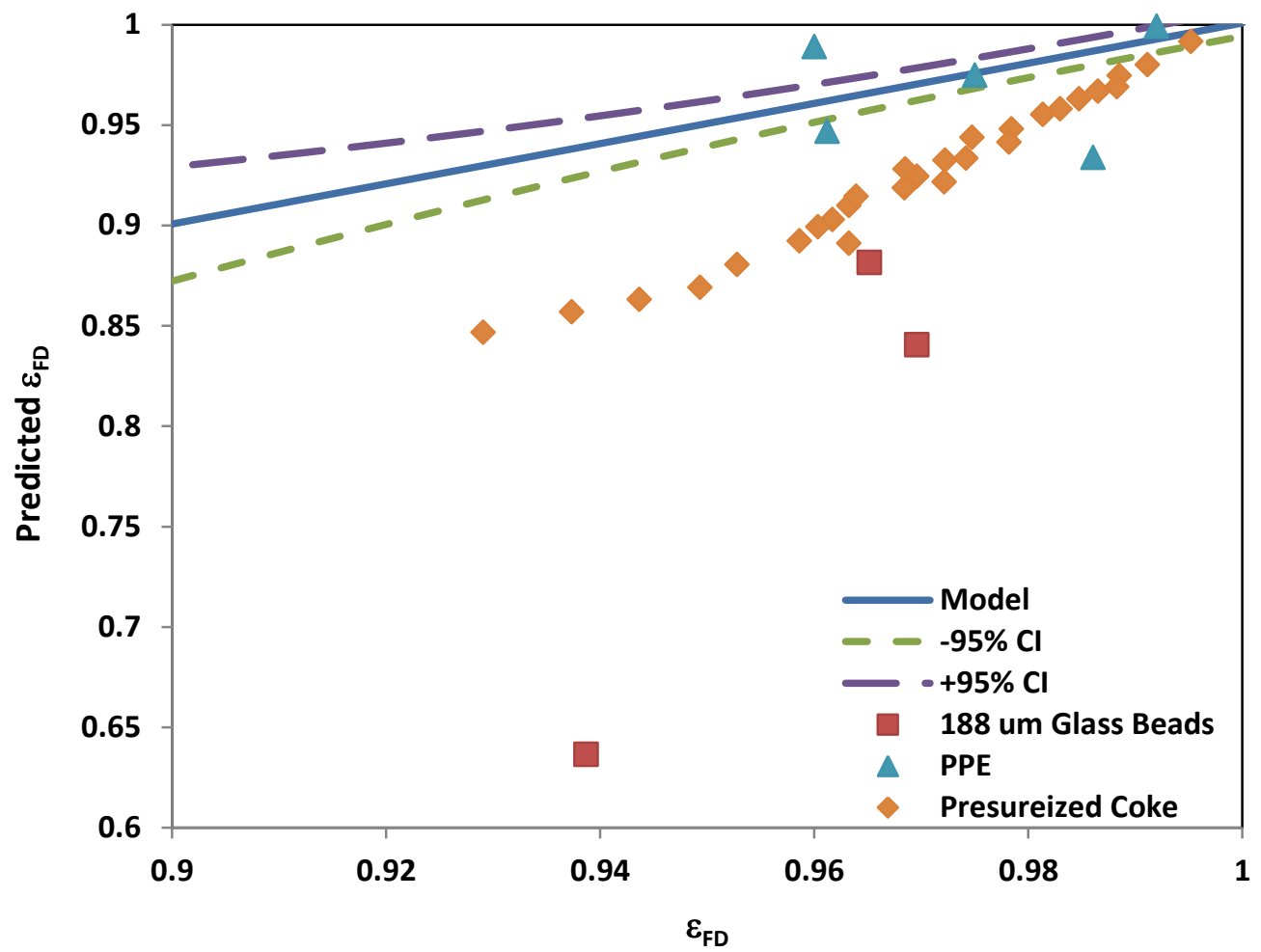

Figure 14 Fully Developed Volume Fraction extended data sets 


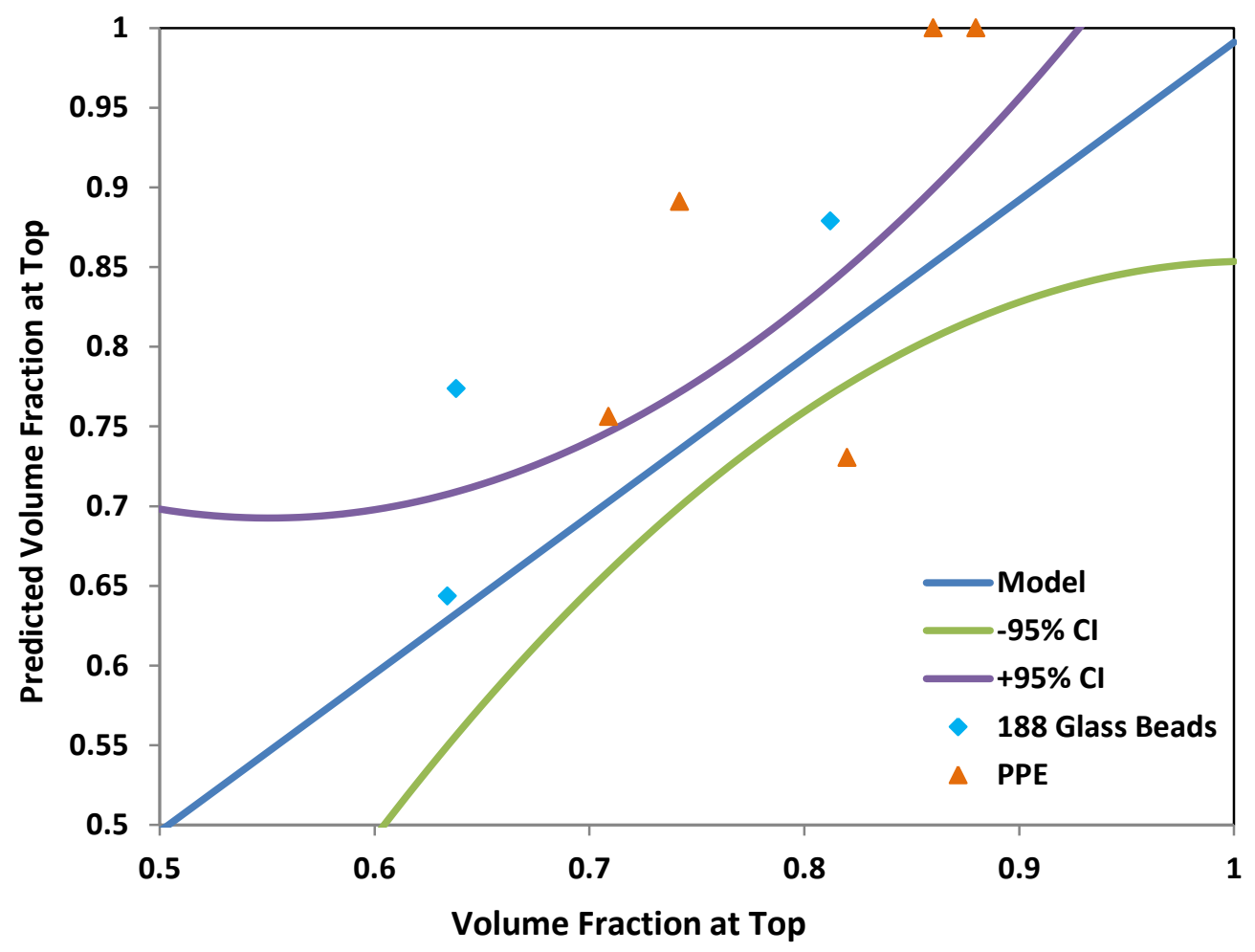

Figure 15 top volume fraction extended data 


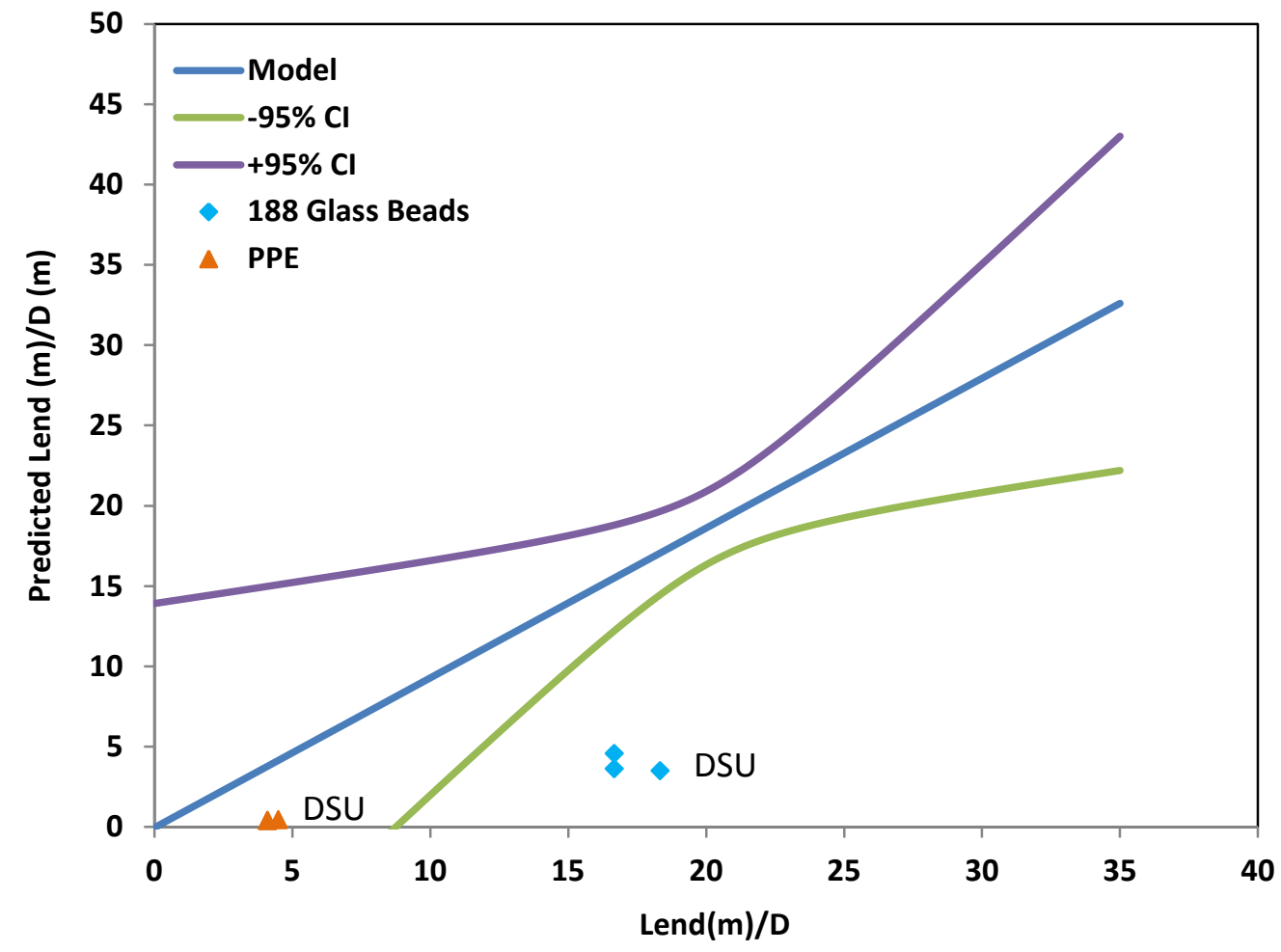

Figure 16. Top exit length extended data sets 